\title{
Modeling and Analysis of Shock Reduction through Counterflow Plasma Jets
}

\author{
Shagufta Rashid $\left(\mathbb{D},{ }^{1}\right.$ Fahad Nawaz $\mathbb{D}^{2},{ }^{2}$ Adnan Maqsood $\left(\mathbb{D},{ }^{1}\right.$ Shuaib Salamat $\left(\mathbb{D},{ }^{1}\right.$ \\ Rizwan Riaz $\left(\mathbb{D},{ }^{1}\right.$ Laurent Dala $\left(\mathbb{D},{ }^{3}\right.$ and Riaz Ahmad ${ }^{1}$ \\ ${ }^{1}$ National University of Sciences \& Technology, Islamabad, Pakistan \\ ${ }^{2}$ Northwestren Polytechnical University, Xi'an, China \\ ${ }^{3}$ Northumbria University, Newcastle, UK \\ Correspondence should be addressed to Adnan Maqsood; adnan@rcms.nust.edu.pk
}

Received 19 February 2021; Accepted 1 June 2021; Published 15 June 2021

Academic Editor: Xingsi Han

Copyright (c) 2021 Shagufta Rashid et al. This is an open access article distributed under the Creative Commons Attribution License, which permits unrestricted use, distribution, and reproduction in any medium, provided the original work is properly cited.

\begin{abstract}
The study presents a numerical investigation of aerodynamic drag reduction by implementing a counterflow plasma jet, emanating from the stagnation point of an aerodynamic surface in a supersonic regime with a constant pressure ratio $(P R=3)$, and compares findings with a conventional opposing jet. The computational study is carried out by solving three-dimensional and axisymmetric Navier-Stokes equations for counterflow plasma-jet interaction. The calculations are performed at free-stream Mach $\left(\mathrm{M}_{\infty}=1.4\right)$ with sea level stagnation conditions. The weakly ionized argon plasma jet generated by a plasma torch has constant stagnation pressure and temperature of $303,975 \mathrm{~Pa}$ and $3000 \mathrm{~K}$. The effect of the Mach number and the angle of attack variation on plasma-jet effectiveness is also analyzed. The results indicate that the counterflow plasma jet reduces more drag (in twice) compared to the conventional jet (nonplasma). The gravitational, magnetic field effect and chemical processes in the plasma formation are considered negligible. It is inferred that the effectiveness of the counterflow plasma jet strongly depends upon the jet stagnation temperature.
\end{abstract}

\section{Introduction}

Reduction in wave drag and thermal conduction is a major design consideration for successful realization of supersonic flight $[1,2]$. The shock waves primarily contribute to significant drag rise and aerodynamic heating. The efforts to reduce wave drag can result in improved payload capacity, long-range, and suppression of acoustic signature. The conventional interventions, introduced in the last century, for shock reduction usually hovered around passive techniques. These techniques include cavity formation on the body nose [3-7] or implementation of a retractable aerospike at the fore-body region [8-12]. However, these passive methods, used to reduce the impact of shock waves, are generally subjected to high aerodynamic and thermal loads and undesirable induced moments during flight maneuvers [13].
The active flow techniques are another area that has been the subject of great discussion to alleviate the undesirable shock characteristics. The counterflow jets can provide the advantage of reducing aerodynamic load by providing virtual disruptive structures. In the early 1950s, the counterflow jet technique was extensively studied due to its effectiveness in drag reduction $[14,15]$. The jet distributes itself under the free-stream influence over the body surface and pushes the shock wave away from the body. The pressure distribution generates two separated low-pressure zones (recirculation regions) ahead of the body [16, 17], as shown in Figures 1(a) and $1(\mathrm{~b})$. These recirculation zones play an important role in the reduction of drag.

The parameters of the counterflow jet have been analyzed experimentally, numerically, and even analytically. Studies [16-21] depict that the jet-to-body diameter ratio, jet orifice shape [22], and pressure ratio [23] affect the jet 


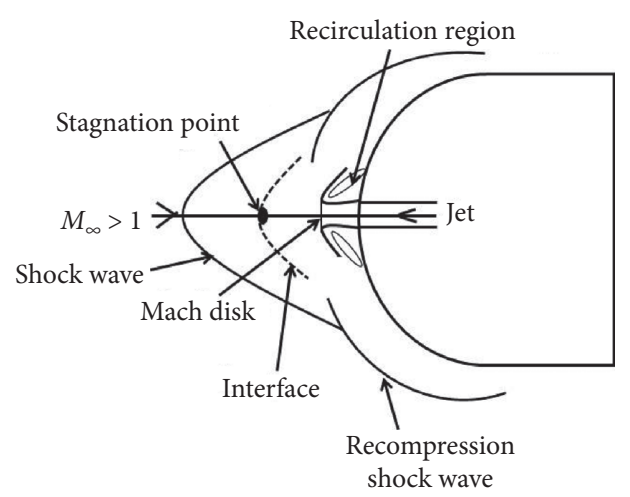

(a)

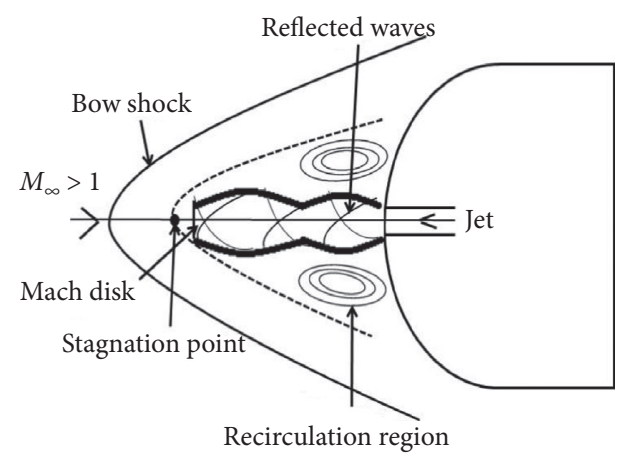

(b)

FIgURE 1: Symbolic illustration of the counterflow jet with two discrete modes. (a) Short penetration mode. (b) Long penetration mode.

performance. The alteration in pressure ratio between the free-stream and counterflow jet generates two operating modes, short penetration mode (SPM) (Figure 1(a)) and long penetration mode (LPM) (Figure 1(b)), determined by the penetration length of the free-stream flow $[24,25]$. The underexpanded jet (LPM) is achieved at low-pressure ratios (PR) [26]. It penetrates the bow shock and displaces it to a maximum distance. LPM mode consists of the weak expansion and compression waves in the form of an unstable diamond-shaped pattern, as depicted in Figure 1(b) [27]. The size of recirculation regions is small and prevails on the leading edge of the body. In contrast, the SPM mode is a stable mode obtained at high-pressure ratios. The recirculation regions are large in width and locate at some distance from the jet region in Figure 1(a) [28]. In consequence, although the penetration length of the flow field is less in SPM than that of LPM, the aerodynamic drag reduced up to $40 \%$, even at smaller jet Mach number [29].

The progress in the counterflow jet technology lead researchers to investigate various other aspects such as influence of different jet ejection materials (water, gases, and plasma) [30-32]. It was realized that supersonic flow passed over the body in the presence of external heat release sources which manifest a 50\%-60\% reduction in drag $[33,34]$. This provoked the scientific community to explore active flow control heated gas injection or energy addition in the flow past for drag reduction. The counterflow plasma (ionized gas) ejection is getting more attention because this technique has the combined effect of counterflow jet and energy deposition. Several experimental and numerical studies are conducted to analyze the effect of the counterflow plasma jet on the aerodynamics of the blunt nose body. Experimentally, researchers found that the injection of the plasma or hot gas against the subsonic, transonic, and supersonic Mach numbers provides twice (or more) drag reduction as compared to air as an ejecting gas [35]. Like conventional jet (nonplasma), several parameters also affect the performance of plasma jet, such as variation in free-stream Mach, pressure ratio (PR), and jet stagnation temperature. However, the value of drag reduction strongly depends on jet stagnation temperature [36].
The seminal research of Fomin [37, 38] observed experimentally as well as numerically that like the conventional jet, the counterflow plasma jet also depicts two operational modes named long penetration mode (LPM) and short penetration mode (SPM). The structure of the two lowpressure zones (recirculation regions) and the flow physics of the plasma jet over the body show the same behavior as that of the conventional jet. However, LPM causes a better reduction in drag due to the penetration of jet into the shock wave $[32,39]$. The jet penetration depends on the value of the pressure ratio [40]. At some specific value, the jet penetrates the bow shock and forms a multibarrel structure (Figure 1(b)); as a result, two small toroidal structures on either side of the body are formed (recirculation regions). The width of these recirculation regions depends on the penetration length of the jet. On medium penetration, the low-pressure zones have a significant effect of drag reduction [41]. This suggests that the dominant fluid dynamics of the counterflow plasma jet, considerably reduced drag even at less mass flow rate because of the high temperature of plasma taken into account. Hence, the reduction in drag due to the plasma jet occurs because of the combined effect of jet-shock interaction and energy addition.

The abovementioned studies justify that the counterflow plasma jet can remarkably reduce drag ahead of the blunt body at supersonic speed. However, a lot of work is carried out for blunt bodies for the ejection of the plasma jet. A few studies exist in which elliptical bodies were used for drag reduction using a counterflow jet technique such as by Love et al. [15]. Recent research was carried out by Rashid et al. [42] in which a conventional counterflow jet was implemented on an airfoil (NACA 0012) nose in supersonic flow to minimize drag. The present investigation focus on the understanding of counterflow ionized gas (plasma jet) in a supersonic regime. The detailed investigation of the counterflow plasma jet is being held on various angles of attack and free-stream Mach numbers. The numerical results of the plasma jet are compared with the conventional jet.

The current article is organized as follows. A brief problem description is formulated in Section 2. The detailed plasma analysis is discussed in Section 3, which includes the plasma generation in a plasma nozzle by using the 
magnetohydrodynamics module. The implementation of the plasma nozzle on airfoil and validation cases are discussed in detail in Section 4. The conditions acquired at the outlet of the plasma nozzle were implemented on the jet region of the airfoil. The influence of the free-stream Mach number and angles of attack on the ejection of the counterflow plasma jet by the constant pressure ratio (PR) are elaborated in Section 5. At last, concluding remarks are discussed in Section 6.

\section{Problem Description}

In this analysis, a generic airfoil (NACA 0012) is selected as a baseline geometry. The airfoil has a blunt leading edge with an adequate thickness to the chord ratio. The airfoil has $1 \mathrm{~m}$ chord with $0.005 \mathrm{~m}$ plasma jet orifice at the leading edge (Figure 2(b)). The computational setup for a generic airfoil is created by using the two-dimensional Reynolds-averaged Navier-stokes equation and turbulence model equation.

The specially designed plasma torch Figure 2(a) is implemented on the nose region of an airfoil, to observe the reduction in drag by injecting plasma in a supersonic free stream. For plasma nozzle study, ANSYS ${ }^{\circledR}$ FLUENT with the magneto-hydrodynamic (MHD) module add-on is applied. A density-based implicit solver is used for all the simulations due to its effectiveness in supersonic flows.

A $2 \mathrm{D}$ and $3 \mathrm{D}$ validation for all the geometries (shown in Figure 2(a)) are followed in this research is a three-step procedure. The grid strategy (Figure 2(b)) for truncated cone and an airfoil remains the same as in [42]. This work emphasized the comparison of the counterflow conventional (nonplasma) jet and hot gas (ionized gas or plasma) ejection. Hence, the air jet ejection case validation is already discussed in [42] with the experimental data of Eugene [15]. Now, in the case of plasma, the computational setup for generated plasma inside the nozzle is validated with the available experimental data of Liu [43].

The results of supersonic counterflow plasma jet ejection for the blunt body are verified with the experimental work of Fomin [38]. The same analogy of Fomin [38] is used for the counterflow ionized gas (plasma) ejection from the leading edge of the generic airfoil. The boundary conditions obtained at the outlet of the plasma nozzle are applied on the pressure inlet of an airfoil in a counterflow plasma jet ejection case.

\section{Plasma Formation}

This section consists of a detailed analysis of plasma generation in the $3 \mathrm{D}$ plasma nozzle. A constant DC voltage is supplied to the heated cathode for the generation of the plasma by utilizing pure Argon gas. The purpose of supplied DC voltage is to provide the required energy to maintain the plasma arc after ionization. To simplify the modeling of plasma arc, it is assumed that the arc column is in local thermal equilibrium (LTE), so all the thermodynamics and transport properties of the fluid are taken as the function of temperature, pressure, and molar fractions of gases. In reality, the partially ionized gas will deviate from the LTE condition especially near the electrodes and in high- temperature gradient zones (called non-LTE regions). In non-LTE conditions, electrons' temperature will be very high as compared to heavy particles. Numerically, the plasma flow physics is described by the magnetohydrodynamic (MHD) module. The governing equations of MHD are the combination of Navier-Stokes equations (for solving fluid dynamics) and Maxwell's equations (to resolve electromagnetism) as depicted in Figure 3. To simplify the plasma generation by MHD model, the following assumptions are made for the plasma arc.

3.1. Model Assumptions. The below-mentioned assumptions are adopted for plasma formation in the plasma nozzle by applying Joule heating to the cathode.

(i) The plasma flow inside the torch is quasi-steady and in local thermal equilibrium (LTE)

(ii) Gravitational effects are negligible

(iii) The plasma is treated as continuum fluid at one temperature for all species and obeys Navier-Stokes equations

(iv) The argon gas is injected axially from the nozzle inlet

(v) In comparison to the applied electric field intensity, the induced electric field is considered insignificant in the plasma arc region

(vi) The chemical reactions are ignored because the main concern of this study is the fluid dynamic properties of plasma, where the nontransferred arc plasma is generated by Joule heating of gas due to the constant current flowing between the cathode and the anode

3.2. Governing Flow Equations. As plasma is the conducting fluid, its flow description requires a solution of the fluid conservation and electromagnetic equations. Based on the preceding assumptions, the $3 \mathrm{D}$ plasma flow modeling is considered valid on fluid dynamics Navier-Stokes and Maxwell electromagnetic equations. For plasma flow dynamics, the Lorentz force becomes the source term of the momentum equation. However, Joule heating becomes the source term of the energy equation. All the generalized forms of equations are represented as follows.

Continuity equation:

$$
\frac{\partial}{\partial t}+\nabla \cdot(\rho v)=0
$$

Conservation of momentum:

$$
\rho\left(\frac{\partial v}{\partial t}+\vec{V} \cdot \nabla \vec{V}\right)=-\nabla p+\nabla \cdot \vec{\tau}+\vec{J} \times \vec{B}+\rho g .
$$

Energy conservation equation:

$$
\frac{\partial \rho h}{\partial t}+\nabla \cdot \rho h \vec{V}-\nabla \cdot \frac{\lambda}{C_{p}} \nabla h=\vec{J} \cdot \vec{E}-S_{\mathrm{rad}}
$$

where the terms in abovementioned equations are $-\nabla p, \vec{\tau}$, $\vec{J} \times \vec{B}, \vec{J} \cdot \vec{E}$, and $S_{\text {rad }}$ are change in pressure, stress tensor, 


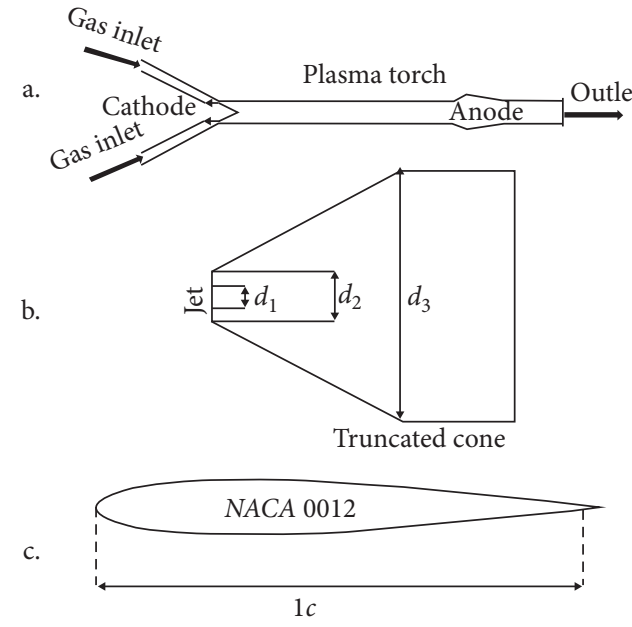

(a)

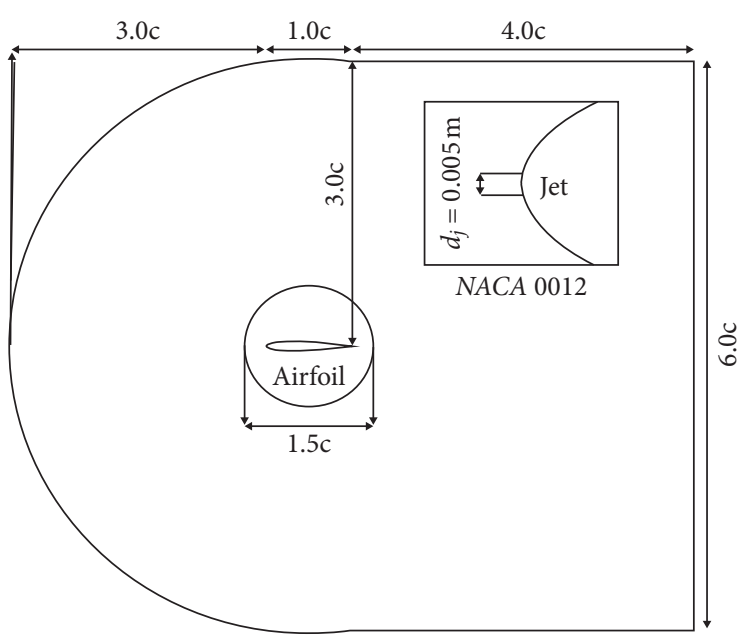

(b)

Figure 2: Geometries with computational domain setup. (a) Schematic of all geometries. (b) Computational domain strategy.

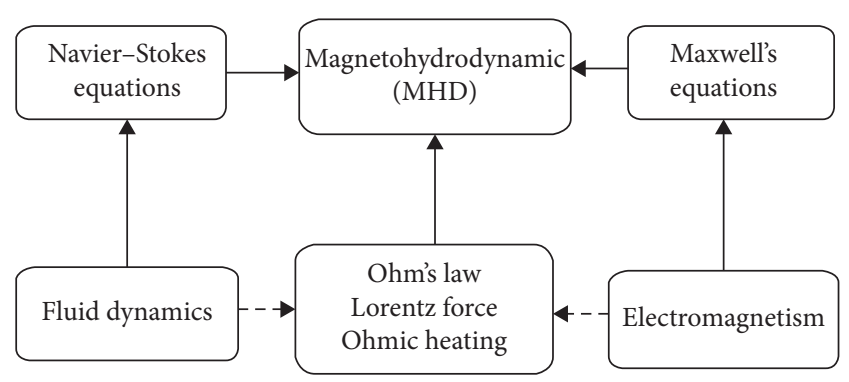

FIgURE 3: Illustration of MHD.

Lorentz force, Joule heating, and volumetric radiation losses, respectively. However, the Lorentz force in equation (2) $(\vec{J} \times \vec{B})$ can be calculated as

$$
\vec{F}=\vec{J} \times \vec{B}
$$

where $\vec{J}$ and $\vec{B}$ represent electric current density $\left(\mathrm{A} / \mathrm{m}^{2}\right)$ and the magnetic field $(T)$, respectively. Here, $\vec{J}$ can be deduced from the generalized Ohm's law:

$$
\vec{J}=\sigma(\vec{E}+(v \times \vec{B})),
$$

where $\sigma, \vec{E}, v$, and $\vec{B}$ represent the electrical conductivity $(\mathrm{S} / \mathrm{m})$, electric field $(\mathrm{V} / \mathrm{m})$, velocity $(\mathrm{m} / \mathrm{s})$ of a particle, and applied magnetic field $(T)$. In this analysis, the magnetic field is neglected; therefore, the current density equation for the steady state electric field becomes

$$
\vec{J}=\sigma \vec{E}
$$

Generally, the electric field value can be calculated by using equation:

$$
\vec{E}=-\nabla \phi-\frac{\partial \vec{A}}{\partial t}
$$

where $\phi$ and $\vec{A}$ are the scalar and vector potentials. By neglecting Neumann's boundary condition, the electric field can be related with the electric potential $\phi(V)$ by the following relation:

$$
\vec{E}=-\nabla \phi
$$

After substituting equation (8) in equation (6), the current density becomes

$$
\vec{J}=-\sigma \nabla \phi
$$

For the adequate conducting material, the principle of conservation of the electric charge gives

$$
\nabla \cdot \vec{J}=-\nabla \cdot(\sigma \nabla \phi)=0 .
$$

However, $\vec{B}$, the magnetic intensity vector, can be calculated by using relation:

$$
\vec{B}=\nabla \times \vec{A},
$$

where $\vec{A}$ is the magnetic vector potential and represented as

$$
\nabla^{2} \cdot A=-\mu_{0} \cdot \vec{J},
$$

which is explicitly solved by using relation:

$$
A=\frac{\mu_{0}}{4 \pi} \int_{\nu} \frac{J}{r} \mathrm{~d} V .
$$

In some studies [44, 45], the modeling of plasma torch is treated as a laminar flow. However, the number of studies [46-48] considered plasma flow as turbulent. It should be noted that, in DC arc plasma torches, sudden heating of projected gas in the nozzle cause change in the acceleration due to the expansion of gas, thereby making the flow turbulent. The widely used turbulent model for the plasma modeling is $k-\varepsilon$, but in the present work, the $k-\omega$ SST model is used because it performs accurate formulation in the near-wall region. The thermal conductivity and the viscosity which appear in the governing equations for plasma modeling include both the contribution of laminar and turbulent components. The $k-\omega S S T$ model was 
selected to simulate the turbulent plasma flow. The turbulent kinetic energy $k$ and the specific dissipation rate $\omega$ can be obtained from the following equations:

$$
\begin{aligned}
& \frac{\partial(\rho k)}{\partial t} \operatorname{div}(\rho k V)=\operatorname{div}\left(\mu+\frac{\mu_{t}}{\sigma_{k}} \operatorname{grad}(k)\right)+P_{k}-\beta^{*}, \\
& \frac{\partial(\rho \omega)}{\partial t} \operatorname{div}(\rho \omega V)=\operatorname{div}\left(\mu+\frac{\mu_{t}}{\sigma_{\omega}} \operatorname{grad}(\omega)\right) \\
& +\gamma_{2}\left(2_{t} S_{i j} \cdot S_{i j}-\frac{2}{3} \rho k \frac{\partial U_{i}}{\partial x_{j}} \delta_{i j}\right)-\beta_{1} \rho \omega^{2}+A_{1},
\end{aligned}
$$

where $P_{k}$ represents the generation of turbulent kinetic energy. However, $\sigma_{k}$ and $\sigma_{\omega}$ are turbulent Prandtl numbers for $k$ and $\omega, \mu_{t}$ is the turbulent viscosity, evaluated as

$$
\begin{aligned}
\sigma_{k} & =\frac{1}{\left(F_{1} / \sigma_{k, 1}\right)+\left(\left(1-F_{1}\right) / \sigma_{k 2}\right)}, \\
\sigma_{\omega} & =\frac{1}{\left(F_{1} / \sigma_{\omega, 1}\right)+\left(\left(1-F_{1}\right) / \sigma_{\omega 2}\right)}, \\
\mu_{t} & =\frac{\alpha_{1} \rho k}{\max \left(\alpha_{1} \omega S F_{2}\right)},
\end{aligned}
$$

where $F_{1}$ and $F_{2}$ are blending functions with strain rate, $S$ is given by

$$
\begin{aligned}
& F_{1}=\tanh \left(\phi_{1}^{4}\right), \\
& F_{2}=\tanh \left(\phi_{2}^{2}\right) .
\end{aligned}
$$

However, $\phi_{1}$ and $\phi_{2}$ are constants represented as

$$
\begin{aligned}
& \phi_{1}=\min \left[\max \left(\frac{\sqrt{k}}{\beta^{*} \omega y}, \frac{500 \mu}{\rho \omega y^{2}}\right), \frac{4 \rho k}{\sigma_{\omega, 2} D_{k y^{2}}}\right], \\
& \phi_{2}=\max \left[2 \frac{\sqrt{k}}{\beta^{*} \omega y}, \frac{500 \mu}{\rho \omega y^{2}}\right],
\end{aligned}
$$

where

$$
D_{k \omega}=\max \left[2 \rho \sigma_{2} \frac{1}{\omega} \frac{\partial k}{\partial x_{j}} \frac{\partial \omega}{\partial x_{j}}, 10^{-10}\right] .
$$

These blending functions $\left(F_{1}\right.$ and $\left.F_{2}\right)$ secure the switching of models $(k-\omega$ SST and $k-\varepsilon)$ for the prediction of far-field flow characteristics. The inner boundary layer is resolved by the $k-\omega$ SST model; however, the outside of the boundary layer are summoned by the standard $k-\varepsilon$ model [49].
The constants for the boundary layer of $k-\omega$ SST are defined as

$$
\begin{aligned}
\sigma_{k_{1}} & =0.85, \\
\sigma_{\omega_{1}} & =0.50, \\
\alpha_{1} & =0.31, \\
\beta_{1} & =0.0750, \\
\beta^{*} & =0.09, \\
k & =0.41, \\
\gamma_{1} & =\frac{\beta_{1}}{\beta^{*}}-\frac{\sigma_{\omega_{1}} K^{2}}{\sqrt{\beta^{*}}} .
\end{aligned}
$$

For outside of the boundary layer, the constant values of the stan $d a r d k-\epsilon$ model are represented as

$$
\begin{aligned}
\sigma_{k_{2}} & =1.0, \\
\sigma_{\omega_{2}} & =0.856, \\
\beta_{2} & =0.0828, \\
\beta^{*} & =0.09, \\
k & =0.41, \\
\gamma_{2} & =\frac{\beta_{2}}{\beta^{*}}-\frac{\sigma_{\omega_{2}} K^{2}}{\sqrt{\beta^{*}}} .
\end{aligned}
$$

3.3. Calculation Domain for the Plasma Nozzle. A simple 3D plasma torch was used for the generation of plasma in these simulations. Based on the nozzle geometry, a simplified computational domain is created, which consists of a cathode, anode, gas flow inlet, and nozzle outlet. A schematic overview with corresponding dimensions of the computational domain is shown in Figure 4(a). The diameters of the nozzle outlet and tungsten rod cathode are $5 \mathrm{~mm}$ and $4 \mathrm{~mm}$, respectively. The insulated walls are represented by solid lines. However, the computational domain consists of the internal region of the plasma torch which comprises 1.58 million nodes with a particular refinement in a near-wall region. A partially enlarged view of the cathode region and the internal mesh of the plasma torch is shown in Figure $4(\mathrm{~b})$. The mesh is dense in the cathode region (Figure 4(b)) to capture the effect of change in temperature and Mach of ionized particles.

3.4. Boundary Conditions. The applied values of the flow conditions for different regions of the plasma torch are listed 


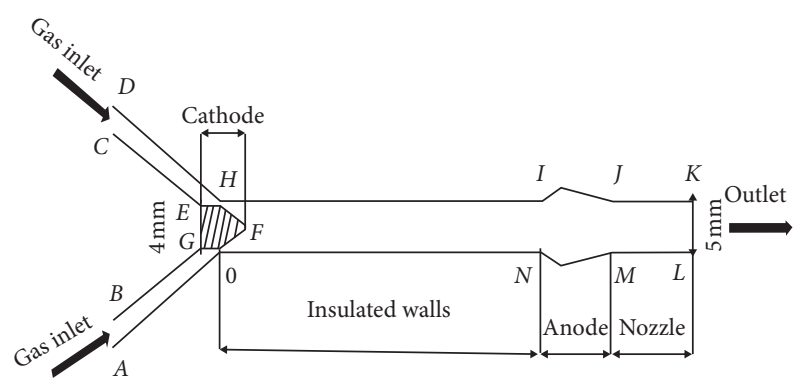

(a)

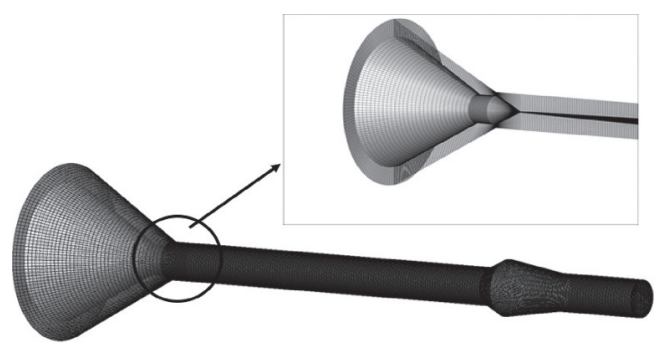

(b)

Figure 4: Computational domain of the plasma nozzle with boundary conditions. (a) Schematic diagram of the plasma torch. (b) Meshing strategy of the plasma nozzle.

in Table 1. The convective heat transfer condition is used for the anode. Temperature-dependent electrical conductivity is employed to predict the electric field inside the plasma nozzle.

The current density and the temperature distributions are defined over the cathode tip. The temperature of the cathode was set as $3000 \mathrm{~K}$ (Table 1) to avoid divergence due to the sudden temperature rise during the plasma formation. Argon is used for plasma gas. The values of thermal conductivity, enthalpy, viscosity, and electrical conductivity for the working gas (Argon) are taken from [50, 51]. Argon gas entered axially into the plasma arc region with the mass flow rate of 8.5 SLPM. The stagnation pressure at the inlet and outlet is taken as $1,01,325 \mathrm{~Pa}$ and $100 \mathrm{~Pa}$, respectively. At the same time, the inlet temperature remains fixed at $288.15 \mathrm{~K}$, whereas the outlet temperature is achieved during the iteration process. For solid walls, a no-slip boundary condition was adopted. In the present study, the plasma is generated by Joule heating by applying direct current (DC) between the cathode and the anode. The anode is set at zero potential; however, the Gaussian-like current density profile $(J(r))$ and temperature distribution were defined at the cathode tip. It was observed that $J(r)$ has no significant effect on the temperature and velocity distribution at the nozzle exit, as the exchange of heat and momentum downstream of the plasma arc can eliminate the bias value $[52,53]$. The current density profile at the cathode tip is defined as

$$
J(r)=J_{0} \exp \left(-\left(\frac{r}{R_{c}}\right)\right)^{n_{c}},
$$

where $J_{0}$ represents the maximum current density at the cathode tip and $r$ is the radial distance from the torch axis. Typically $J_{0}$ and $n_{c}$ are defined as the shape of the current density profile. For $J_{0}=3 \times 10^{8} \mathrm{~A} / \mathrm{m}^{2}$ and $n_{c}=5$, the value of $R_{c}$ is calculated to ensure that the integration of $J(r)$ over the cathode tip is equal to the total applied current of $300 \mathrm{~A}$.

3.5. Validation of Plasma Nozzle Setup. The plasma nozzle geometry and boundary conditions for plasma torch validation are extracted from the work of Sen-Hui Liu [43]. The ionized gas comprises the mixture of $70 \%$ nitrogen and $30 \%$ argon. The plasma generation conditions for validation remains the same as in Table 1 except the inlet $(1.1 \mathrm{~atm})$ and outlet ( $1 \mathrm{~atm}$ ) pressure values. However, the value of current for the validation case was taken to be $160 \mathrm{~A}$ at a current density of $J_{0}=10^{8} \mathrm{~A} / \mathrm{m}^{2}$. The comparison of current density between numerical and experimental data shows reasonable agreement in Figure 5.

The current density is maximum at the cathode tip due to the ionization of the mixture of gases. The ionization is maximum in the central region near the cathode tip. When gas passes near the heated cathode, it will experience strong heating that causes an increase in kinetic energy of gas molecules which leads to the ionization of the gas. This produced maximum current density in the central region near the cathode tip, but propagation along the radial direction of plasma torch current density starts decreasing, as can be seen in Figure 5 .

3.6. Plasma Flow Structure inside the Nozzle. For the present numerical analysis, argon gas with boundary conditions mentioned in Table 1 was used. The flow structure of plasma inside the nozzle can be understood with the help of Figure 6. It (Figure 6) illustrates that the plasma flow structure can be divided into three radial zones: hot core zone, transition zone, and cold flow zone. The hot core region is mostly represented by temperatures greater than $6000 \mathrm{~K}$, and the gas is considered as plasma (ionized gas). This zone can be further divided into two regions: one near the cathode tip where the temperature is higher than $18,000 \mathrm{~K}$, and the second located after the first zone where the temperature is lower than $18,000 \mathrm{~K}$. Farther away radially along with the nozzle, the temperature starts decreasing, which represents the transition zone (point $b$ ), which was at low temperature than $a$. Similarly, point $c$ is in the cold flow zone and has the least temperature as compared to other zones (Figure 6).

\subsection{Temperature and Velocity Profiles of Plasma.} Figure 7 (a) illustrates the axial temperature distribution inside the plasma nozzle at different cross sections. It can be noticed that the strong heating effect of the plasma arc results in a very high-temperature region behind the cathode. This high-temperature region is conserved in the center of the plasma torch (Figure 7(c)). The high-temperature $(18000 \mathrm{~K})$ plasma arc column expands axisymmetrically from the cathode to the anode. Due to heat conduction, the 
TABLE 1: Boundary conditions of the plasma torch.

\begin{tabular}{|c|c|c|c|c|c|}
\hline Regions & Prescribed boundary & $T(\mathrm{~K})$ & $V(\mathrm{SLPM})$ & $P(\mathrm{~Pa})$ & $\phi(\mathrm{V})$ \\
\hline Outlet & LK & $\partial T / \partial n=0$ & $\partial V / \partial n=0$ & 100 & $\partial \phi / \partial n=0$ \\
\hline Anode & $\mathrm{IJ} / \mathrm{NM}$ & 500 & 0 & $\partial P / \partial n=0$ & 0 \\
\hline Walls & DHI/JK/AON/ML/CE/GB & 288.15 & 0 & $\partial P / \partial n=0$ & $\partial \phi / \partial n=0$ \\
\hline Cathode & EFG & 3000 & 0 & $\partial P / \partial n=0$ & $J(r)$ \\
\hline Gas inlet & $\mathrm{CD} / \mathrm{AB}$ & 288.15 & 8.5 & 101325 & $\partial \phi / \partial n=0$ \\
\hline
\end{tabular}

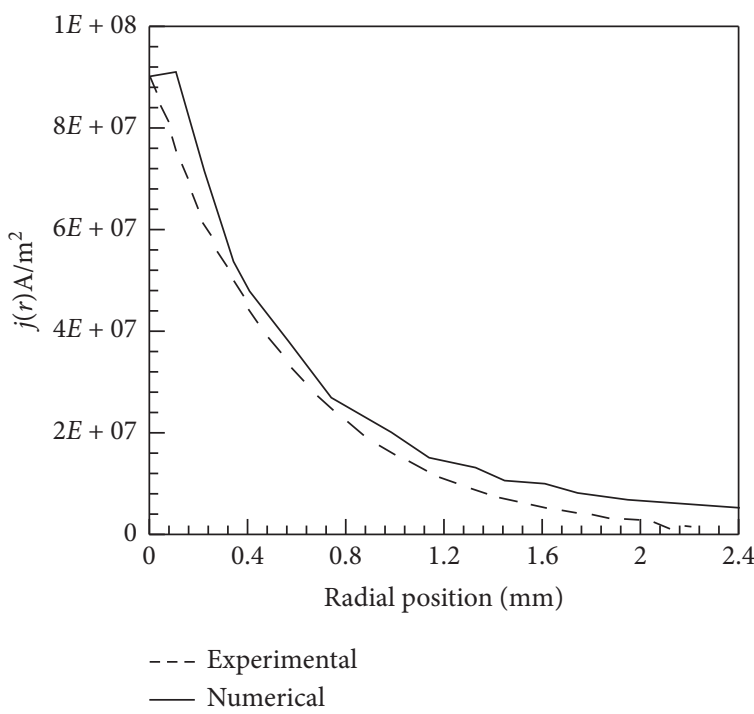

FIgURE 5: Current density comparison.

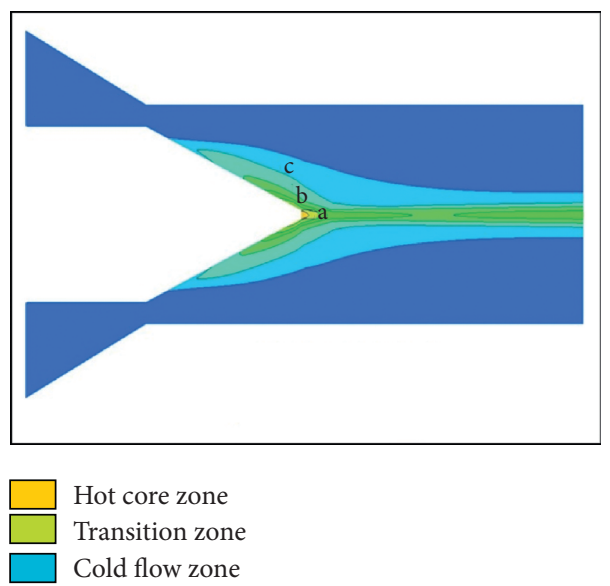

Figure 6: Plasma flow structure inside the nozzle.

temperature of the plasma arc decreases with the increase in axial distance from the cathode tip, as shown in Figure 7(a). Due to the continuous flow of gas through the plasma arc, it is significantly heated up and maintains a relatively high temperature at the nozzle exit. Additionally, a diffusive arcroot is established for argon gas at the anode wall, which developed a relatively high-temperature region at the anode root attachment (Figure $7(\mathrm{e})$ ) due to the current passing through the anode. After evacuation from the anode, the reduction in temperature occurs because the hot jet emerges from the nozzle exit.
The velocity distribution of plasma is almost axisymmetric and its behavior depends on the temperature distribution. In the vicinity of the cathode, where the temperature is high enough due to Ohmic heating, plasma velocity increases, with the increase in axial distance from the cathode tip (insulated region), the velocity starts decreasing. It can be noted from Figure $7(\mathrm{~d})$ that the highvelocity region exists in the center of the plasma torch as a result of a rapid rise in the temperature that causes the expansion of gas, which leads to an appreciable accelerating effect. This accelerating effect leads the high-velocity 


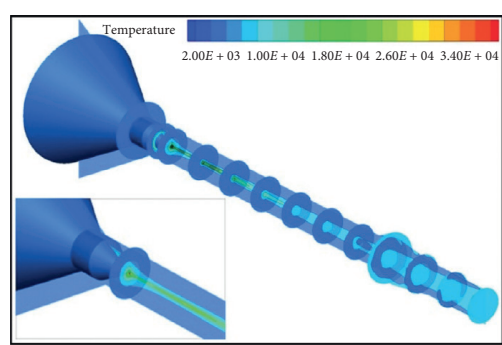

(a)

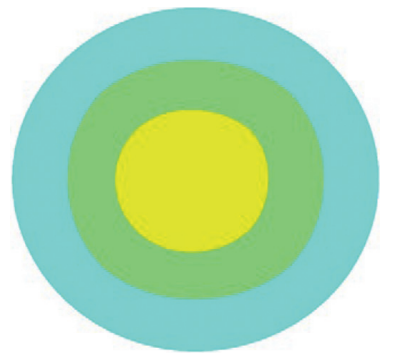

(d)

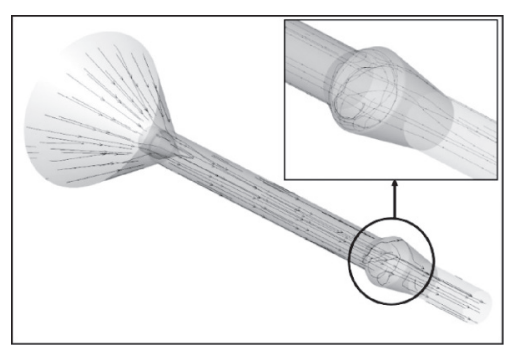

(b)

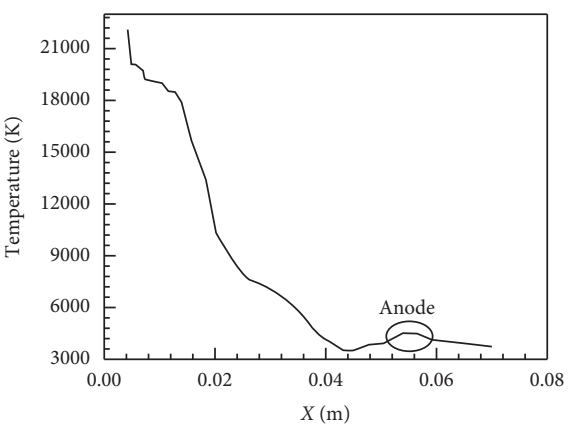

(e)

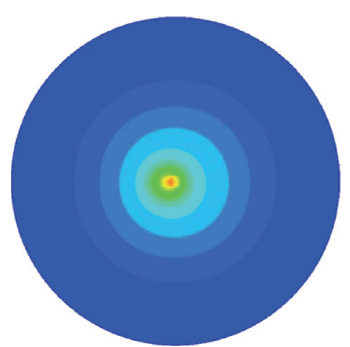

(c)

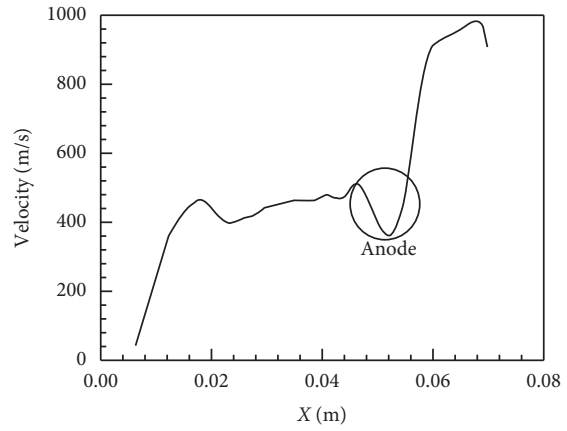

(f)

Figure 7: Change in temperature and flow velocity inside plasma torch. (a) Axial temperature distribution. (b) Flow velocity inside the plasma torch. (c) Radial temperature distribution. (d) Radial velocity distribution. (e) Graphical representation of axial temperature. (f) Graphical illustration of axial velocity.

particles (electrons) to the anode, where these particles slow down (Figure $7(\mathrm{f})$ ) due to the high particle density. However, the high density creates maximum Joule heating that provides a high value of the electric current. The flow accelerates due to excessive Joule heating in the anode region and forms two discrete vortices upstream and downstream of the anode, as depicted in Figure 7(b). The accelerated flow evacuated from the nozzle exit with one order of magnitude has greater velocity than that near the cathode tip. In the present analysis, the maximum velocity on the nozzle exit reaches about $1000 \mathrm{~m} / \mathrm{s}$.

\subsection{Mach and Pressure Distribution inside Plasma Nozzle.} For any selected gas, the nozzle geometry and ohmic heating define the change in the Mach number and static pressure along with the nozzle. Usually, the value of the Mach number and static pressure is evaluated by assuming isentropic flow in the nozzle [54].

Analogous to velocity, the high temperature near the cathode tip causes a rapid increase in axial Mach (Figure 8(c)) which is maintained (Figure 8(a)) in the center of the plasma nozzle. With the increase in the axial distance from the cathode to the anode, the Mach number also increases, as the high-velocity particles accelerate towards the anode with great velocity. However, the Mach number of the accelerated particles sharply decrease (Figure $8(\mathrm{c})$ ) at the anode as a result of an increase in stagnation pressure. However, these high-velocity particles (electrons) perform vortex flow, as shown in Figure 7(b). This vortex flow accelerates the ionized particles (electrons), causes a rise in Mach again (Figure 8(c)), and attains a near-supersonic value. Hence, at the nozzle exit, flow persists sonic Mach $($ Mach $=1)$.

In contrary to the Mach number, axial pressure distribution inside the nozzle decreases in the direction of flow, from the gas inlet to the outlet (Figure 8(b)). A strong pressure gradient near the cathode region is established by the electromagnetic force, due to the high current density, as mentioned in Figure 8(d). The reduction in pressure takes place downstream of the cathode area. However, at the anode, depletion in Mach intensifies the pressure, as depicted in Figure 8(d), by high current density.

\subsection{Turbulent Kinetic Energy and Current Density Distribu-} tion in the Plasma Nozzle. The high temperature and applied DC voltage at the cathode generate considerable turbulence in the employed gas. Figure 9(a) illustrates that the turbulent kinetic energy maintains a maximum value in the center of the plasma nozzle. The high-temperature ionized flow propagates from the center of the nozzle towards the anode. This change results in a high value of turbulent kinetic energy in the center that looks in the form of an arc. The empirical representation in Figure 9(c) illustrated that increase in the axial distance from the cathode causes a reduction in turbulent kinetic energy. Nonlinearity in the graph depicts the dissipation and retrieval of energy by ionized particles due to collision with other particles. In the anode region, turbulent kinetic energy regains its value due to the collection of high-energy ionized particles.

Similar to turbulent kinetic energy, the current density $(J)$ of thermionic emission also depends on cathode surface temperature. Unless the temperature does not gain a 


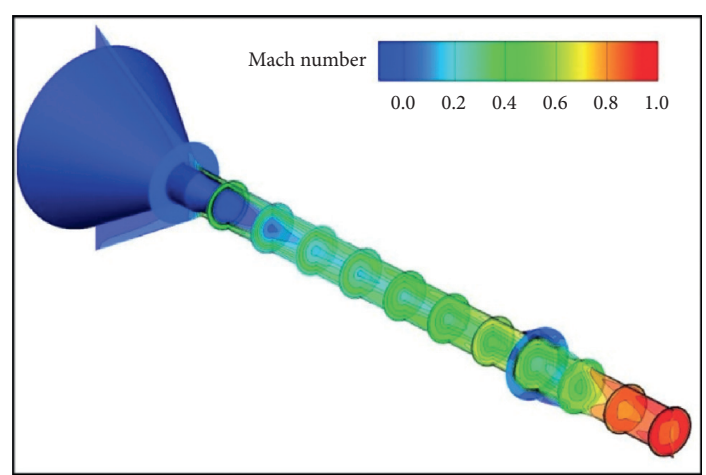

(a)

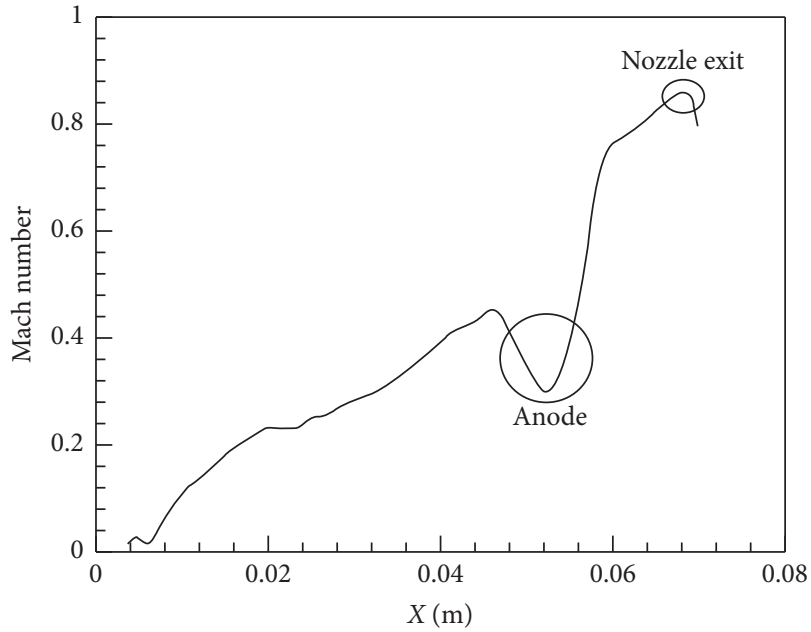

(c)

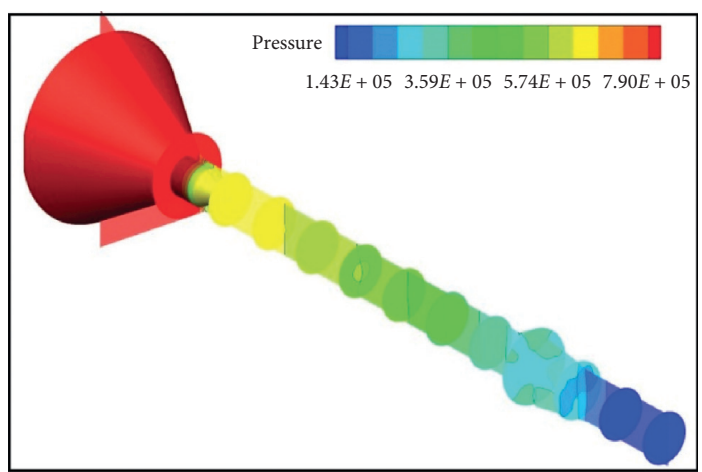

(b)

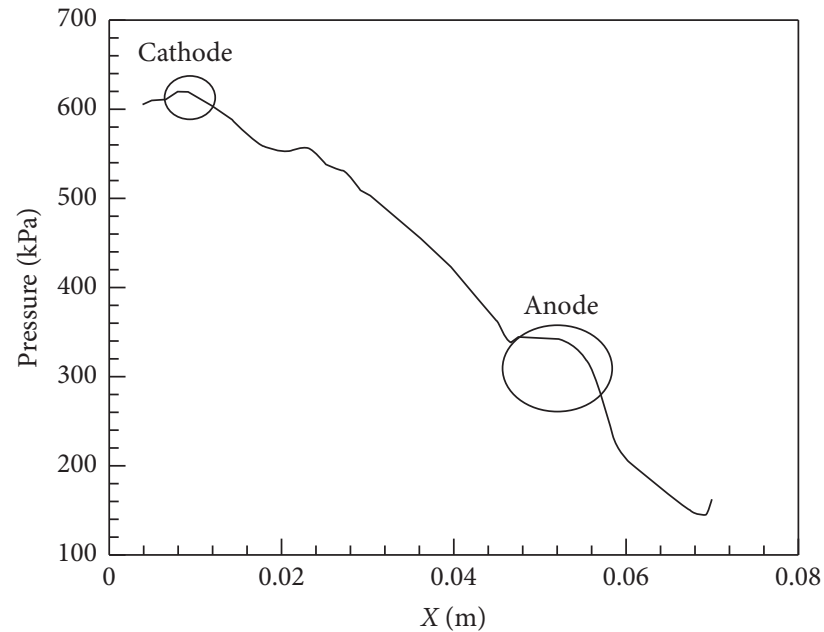

(d)

FIgURE 8: Change in Mach and pressure inside the plasma torch. (a) Axial Mach number distribution. (b) Axial pressure distribution. (c) Graphical illustration of the Mach number. (d) Graphical demonstration of static pressure.

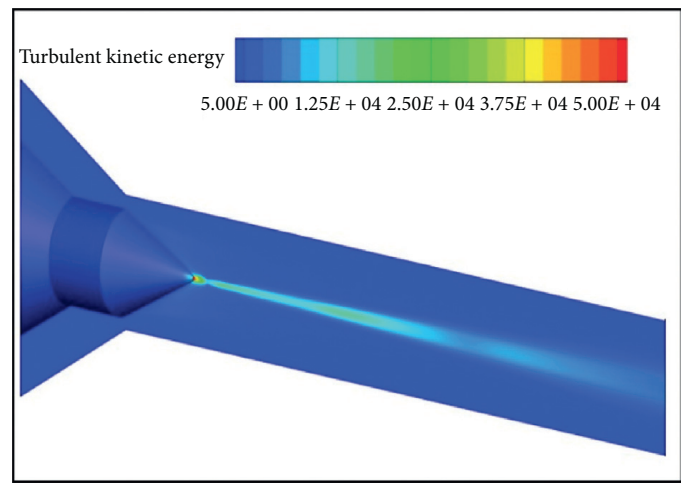

(a)

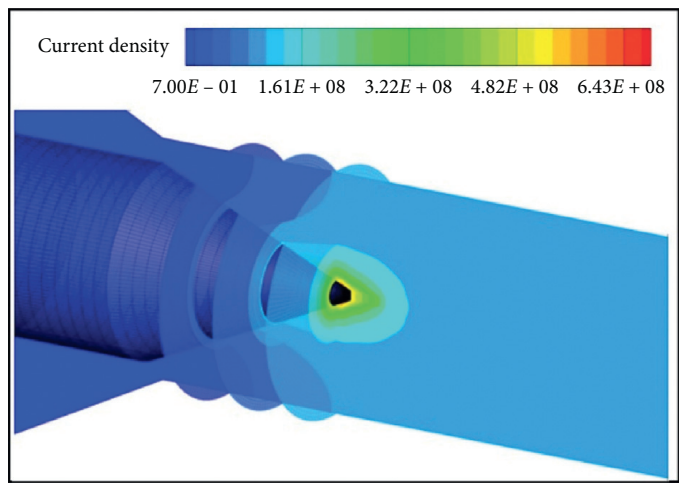

(b)

Figure 9: Continued. 


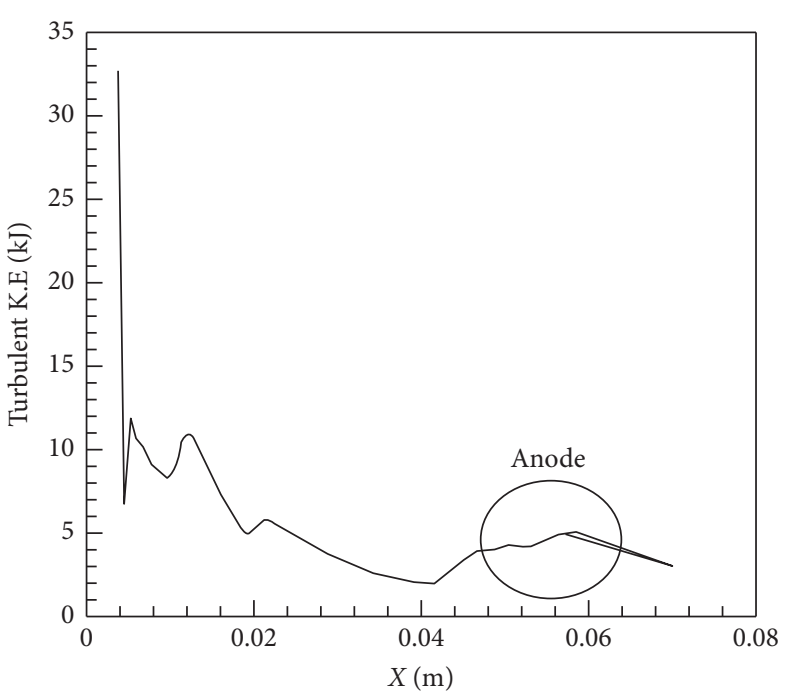

(c)

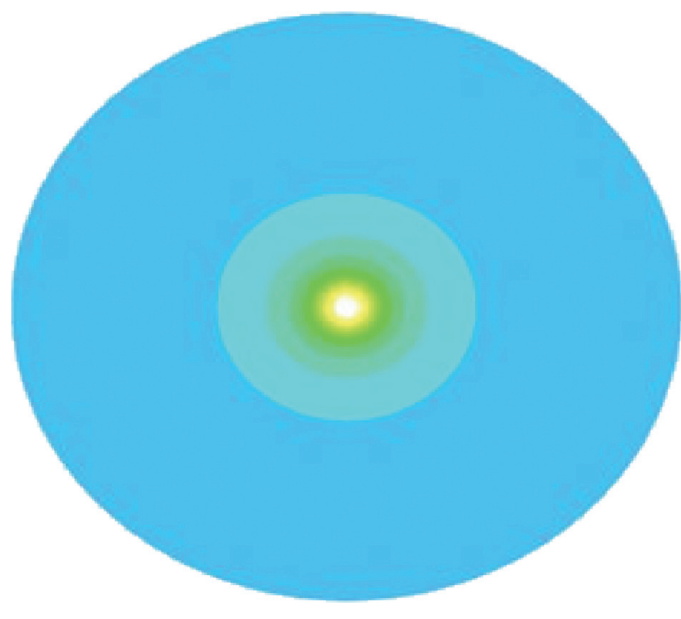

(d)

Figure 9: Change in current density and turbulent kinetic energy inside the plasma torch. (a) Turbulent kinetic energy. (b) Current density. (c) Axial distribution of turbulent K.E. (d) Radial current density distribution.

threshold value, it is not possible to achieve the current density encountered in the plasma arc. The maximum current density value exists near the cathode tip, due to the high-temperature gradient that causes a high degree of ionization. The value of high current density propagates towards a low potential (anode) (Figure 9(b)) and manifests the plasma arc-root attachment. The attachment of the plasma arc with the anode induces a rise in the value of current density again just like temperature behavior (Figure $7(\mathrm{e})$ ). The axial current density conserved the total current value inside the torch. However, in the radial direction (Figure $9(\mathrm{~d})$ ), the value of current density is decreased on propagation from the hot core region to the cold zone. The temperature of ionized gas drops on mixing with cold gas from the inlet. This reduction in the temperature generates depletion in current density far from the cathode (cold zone).

\section{Counterflow Plasma-Jet Ejection}

After generation of onboard argon plasma with the help of the plasma nozzle, the torch was installed on generic airfoil for ejection of the counterflow plasma jet from the leading edge of the airfoil to observe drag reduction in supersonic flow. Fomin [38] was the first who executed the concept of a counterflow plasma jet on the truncated cone for drag and heat reduction in supersonic and hypersonic flows. So, in the present analysis, the computational method is first validated with experimental results of Fomin [38], by applying the same boundary conditions on the truncated cone.

4.1. Computational Setup and Associated Validation. In the current investigation, a NACA 0012 airfoil is selected as a reference aerodynamic body. The airfoil has a blunt leading edge with a chord length of $1 \mathrm{~m}$. The jet diameter is taken as $5 \mathrm{~mm}$ at the leading edge. However, the meshing strategy remains the same (Figure 10(a)) as used in [42] except the installation of the plasma nozzle (Figure 10(b)). In a fully structured mesh with boundary conditions, pressure inlet, pressure outlet, and pressure far-field are selected to model the flow structure. By utilizing isentropic relations, mentioned in equation (22), the static pressure and temperature $\left(P_{\infty}, T_{\infty}\right)$ can be calculated under sea-level stagnation conditions $\left(P_{0 \infty}, T_{0 \infty}\right)[17]:$

$$
\begin{aligned}
& \frac{P_{o_{\infty}}}{P_{\infty}}=\left[1+\frac{\gamma-1}{\gamma} M^{2}\right]^{(\gamma /(\gamma-1))}, \\
& \frac{T_{o_{\infty}}}{T_{\infty}}=\left[1+\frac{\gamma-1}{\gamma} M^{2}\right] .
\end{aligned}
$$

The interaction of the counterflow plasma jet from the leading edge of an airfoil with the free stream was modeled by using ANSYS ${ }^{\circledR}$ Fluent. Two-dimensional unsteady Reynolds-averaged Navier-Stokes (URANS) and turbulence model equations were solved using a density-based implicit solver, as it works effectively for supersonic flows. The ideal gas law was used to model the flow properties in the far-field. This numerical approach successfully summarizes the dynamics of the counterflow plasma jet and its associated multiple shock pattern after interaction of the internal nozzle and external supersonic flow.

The experimental data generated by Fomin [38] for a truncated cone is validated numerically for the counterflow plasma jet. The parameters of truncated cone were cone halfangle $\phi=30 \mathrm{deg}$, ratio of midsection diameter $d_{3}$ to the jet diameter $d_{1}$ of $5: 1$, and $d_{1}: d_{2}=1: 4$. The free-stream conditions include Mach number $\mathrm{M}_{\infty}=2$, angle of attack $\alpha$ $=0$ with total temperature and pressure of $T_{0 \infty}=283 \mathrm{~K}$, and $P_{0 \infty}=1$ atm. However, Mach of jet $\left(M_{j}\right)$ at the inlet exit is 


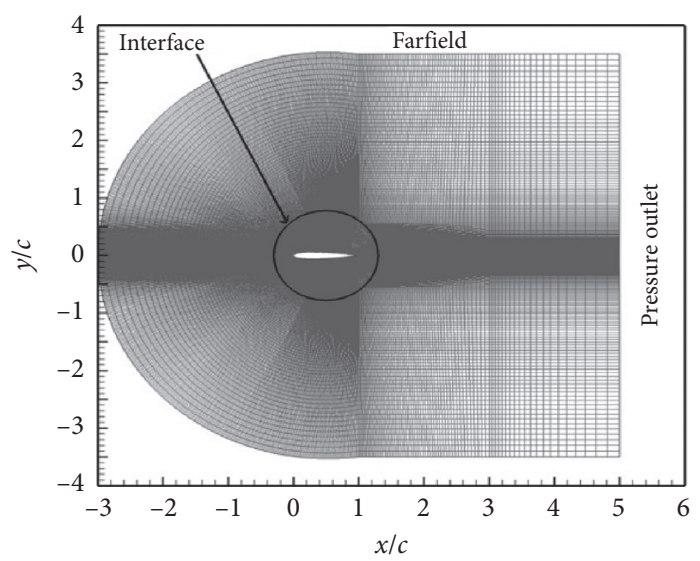

(a)

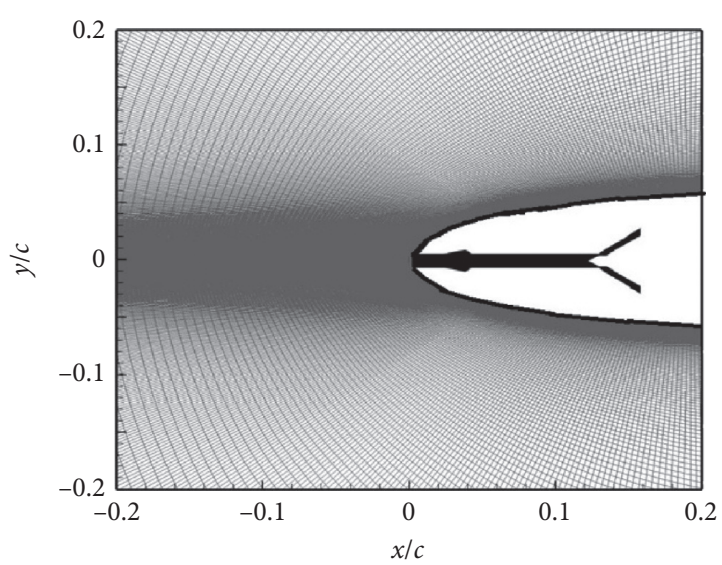

(b)

FIgURE 10: Meshing strategy of generic airfoil. (a) Meshing domain. (b) Zoom in view.

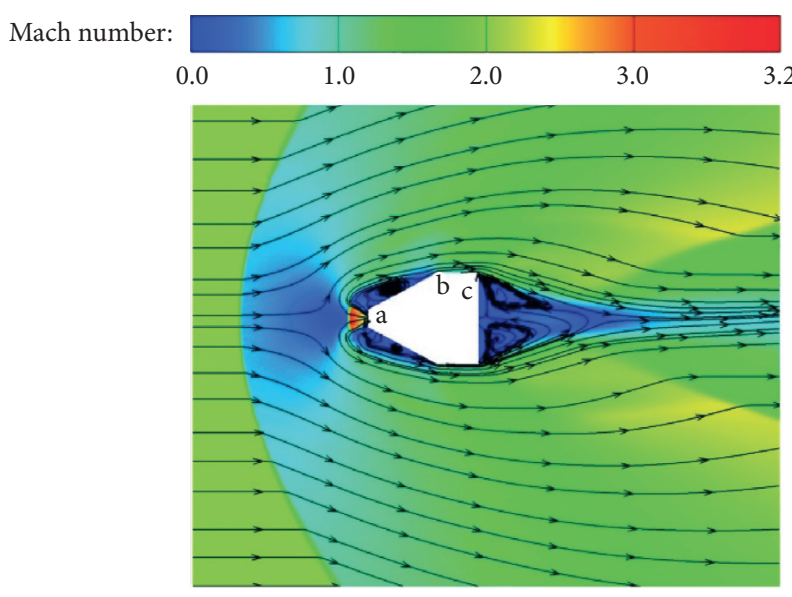

(a)

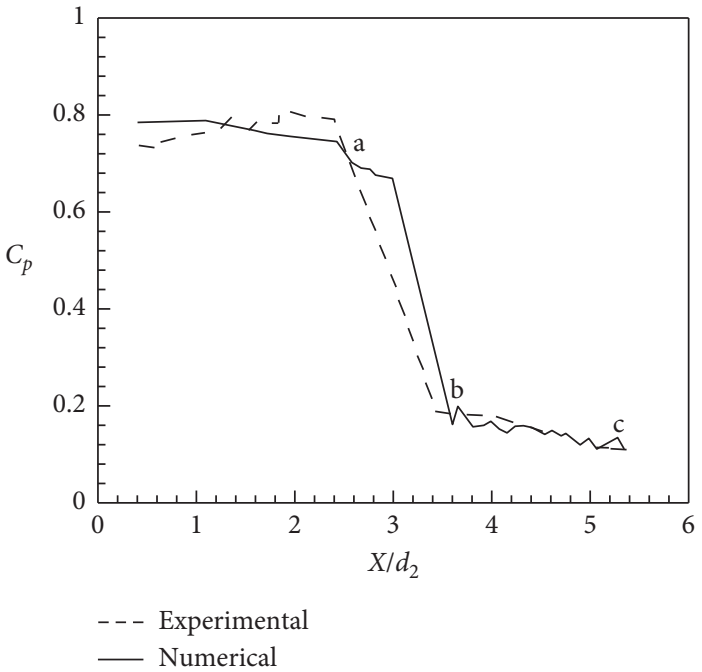

(b)

FIGURE 11: Drag reduction over the truncated cone by implementing the plasma jet. (a) Mach distribution over the truncated cone with the plasma jet. (b) Surface pressure comparison over the truncated cone with the plasma jet.

unity. Total jet temperature was considered as $T_{0 j}=5000 \mathrm{~K}$ with a specific heat ratio value, $\gamma=\left(c_{p} / c_{v}\right)=1.4$. The pressure ratio $P$ was defined as

$$
P=\frac{p_{0 j}}{p_{0 f}^{\prime \prime}}
$$

where $p_{0 f}^{\prime}$ is the stagnation pressure downstream of the shock wave and $p_{0 j}$ is the jet stagnation pressure. The numerical results were compared only for SPM mode with the experimental data at $P=1.7$. The graphical representation of pressure coefficient in Figure 11(b) depicts good agreement between experimental and current numerical results.

In Figure 11(b), surface pressure is plotted against dimensionless coordinate $\left(X / d_{2}\right)$, where the value of $d_{2}=9 \mathrm{~mm}$. Figure 11(b) exhibits the efficiency of the counterflow plasma jet that pushed the shock wave away from the body and provide a reduction in drag. Though edges of the truncated cone are covered by recirculation regions (low pressure zones) that vanish the effect of the oblique shocks, as shown in Figure 11(a), the pressure from point $a$ to $b$ drops drastically (Figure 11(b)) because the lowpressure zones (re - circulation regions) cover the body up to point $b$. From point $b$ to $c$, decrease in pressure becomes steady (Figure 11(b)). Our numerical results also support the findings of Fomin [38].

\section{Flow Characteristics of the Counterflow Plasma Jet}

In supersonic flow, the bow shock is formed ahead of the aerodynamic surface and contributes to an increase in drag and heat. This study compares the efficiency of conventional (counter flow air jet) and counterflow plasma jet to alleviate 

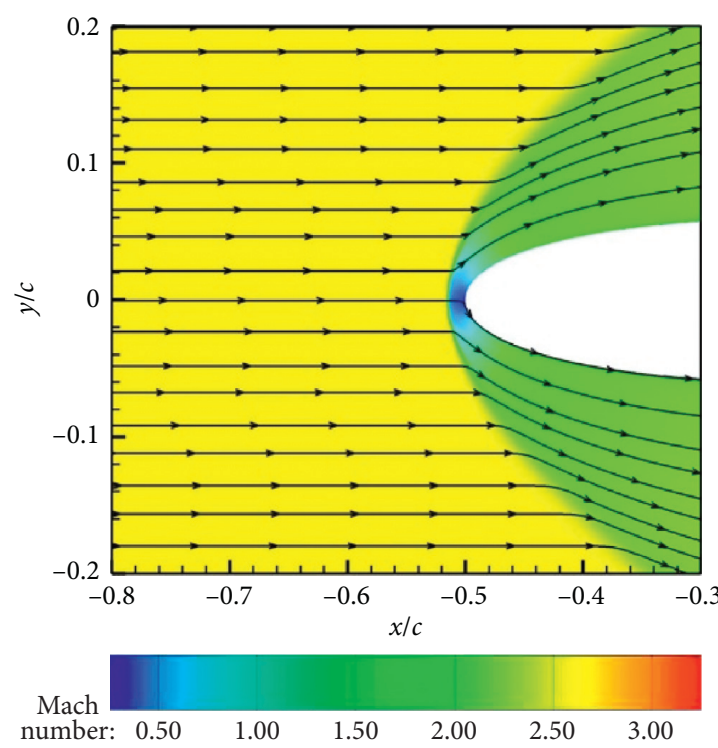

(a)
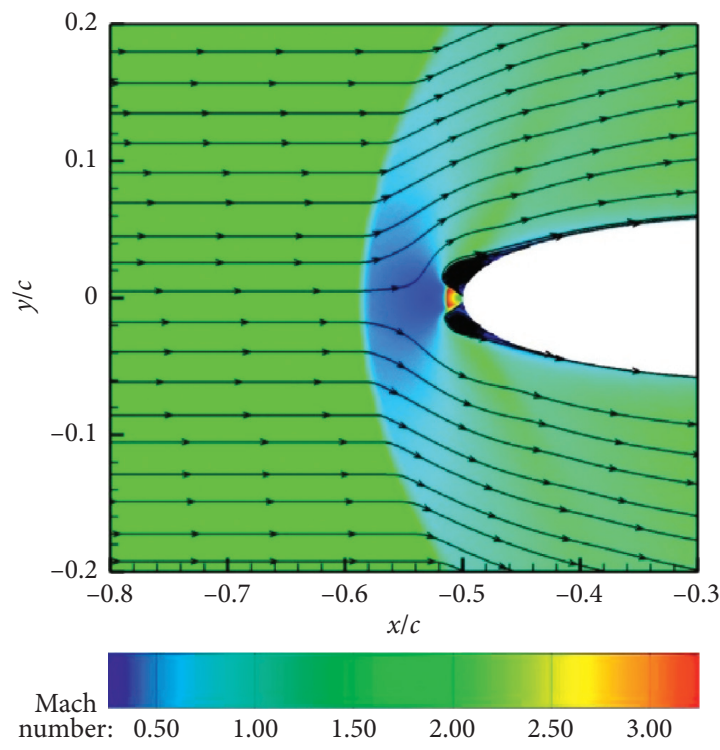

(c)
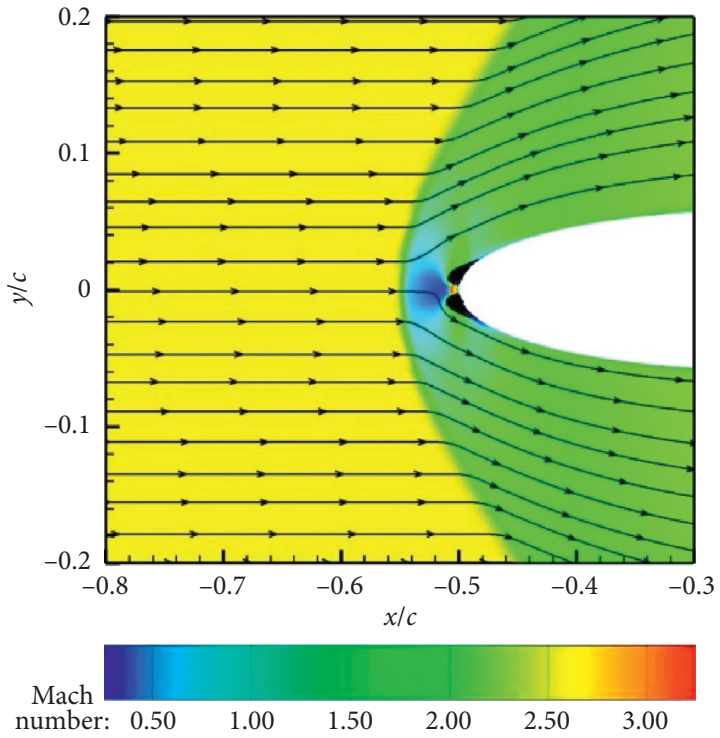

(b)

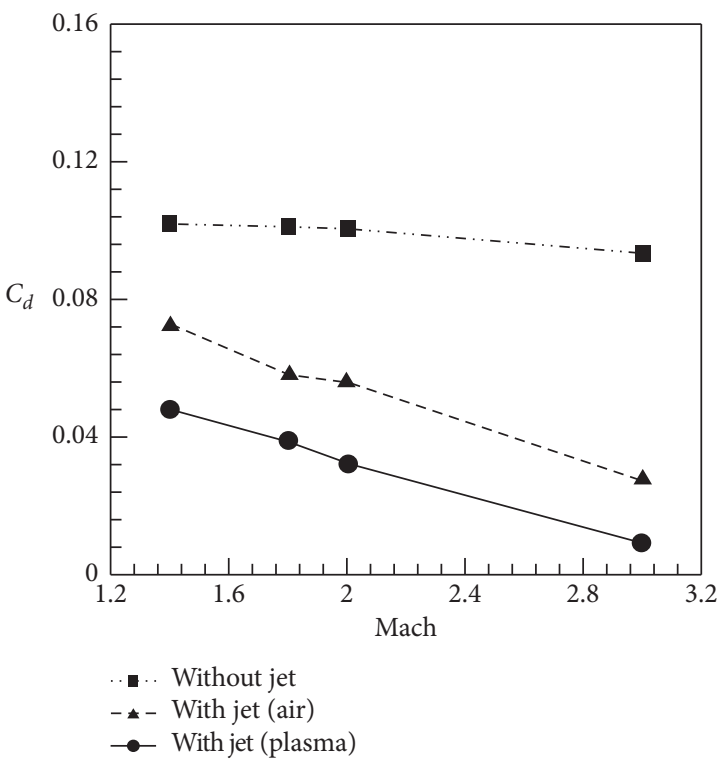

(d)

Figure 12: Comparison of drag between without jet, plasma, and conventional jet. (a) Without jet. (b) With jet (air). (c) With jet (plasma). (d) Comparison of drag for three cases.

drag on the leading edge of the airfoil. The fluid dynamics of the plasma jet are almost the same as that of the conventional jet in moderate supersonic flow. The impact of variation in angles of attack and Mach number is investigated in detail such that effective drag reduction can be computed for both (air and plasma) counterflow jets. To analyze the performance of both jets, free stream and jet conditions for plasma and conventional jets remain the same. The jet Mach is unity $\left(M_{j}=1\right)$ and jet stagnation temperature is $T_{0 j}=3000 \mathrm{~K}$. However, at constant $\mathrm{PR}=3$, the free-stream Mach, $\left(M_{\infty}=1.4\right)$, stagnation pressure and temperature are $101325 \mathrm{~Pa}$ and $288.15 \mathrm{~K}$.
5.1. Effect of Mach Number Variation. Analogous to the conventional jet, the counterflow plasma jet is also influenced by different parameters; among them, free-stream Mach is the key parameter that governs the plasma jet flow structure. In the plasma jet, a significant reduction in drag was observed, compared to the conventional jet (Figure 12(d)). The increment in free-stream Mach number $\left(M_{\infty}=1.4\right.$ to 3.0$)$ enhanced the reduction in the drag coefficient $\left(C_{d}\right)$. Pressure ratio, PR of 3 , and Mach of jet, $M_{j}$, equal to unity was used to dislocate the shock wave ahead of an airfoil, which substantially helped in the depletion of the drag coefficient. 

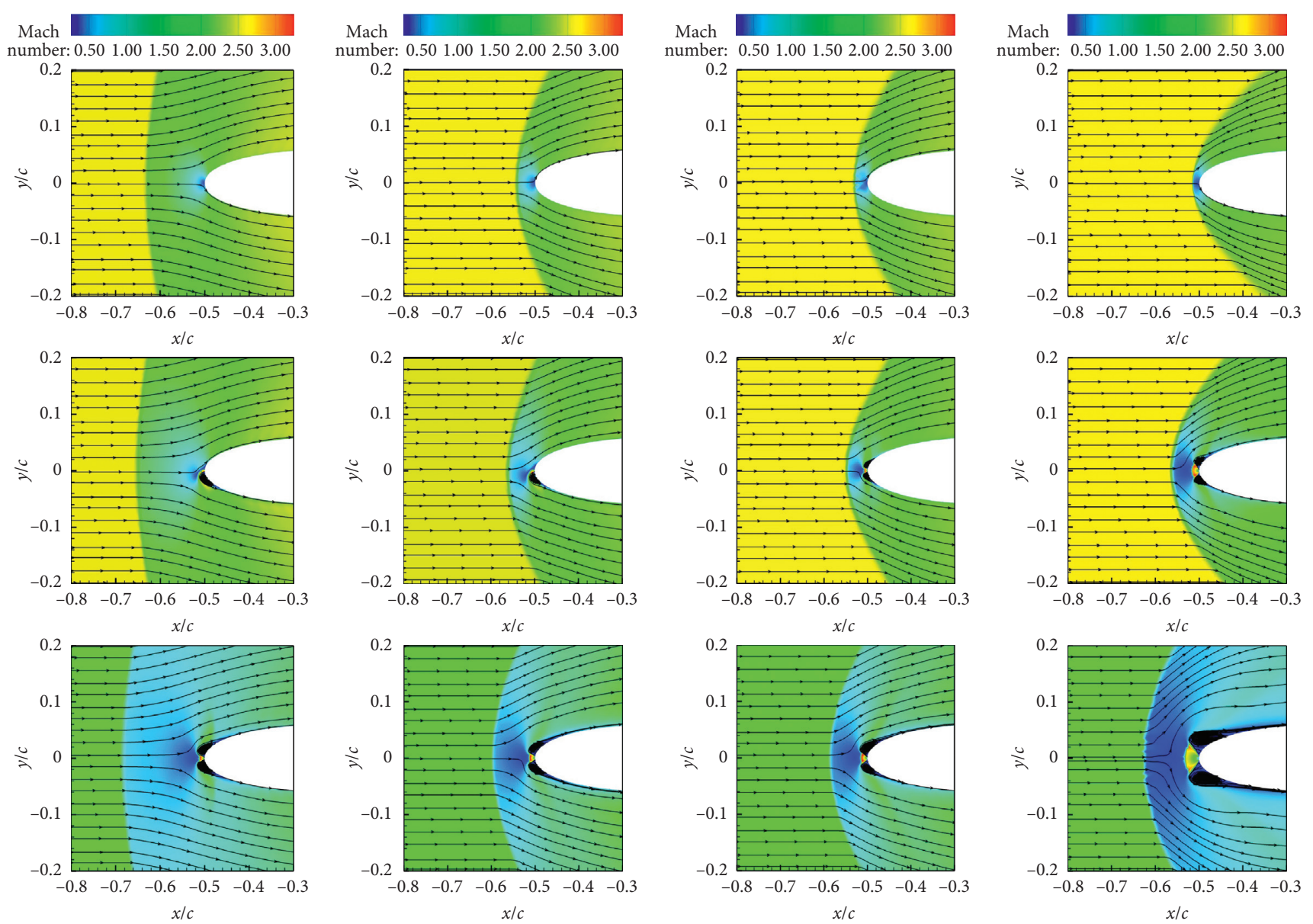

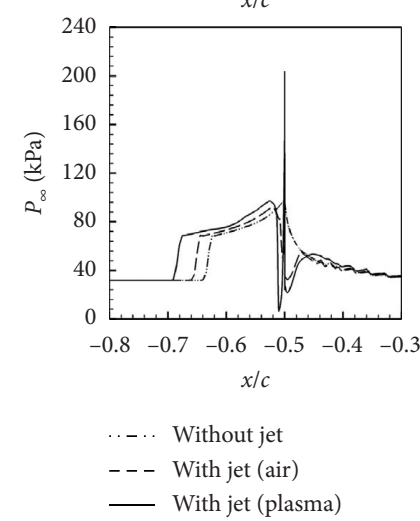

(a)

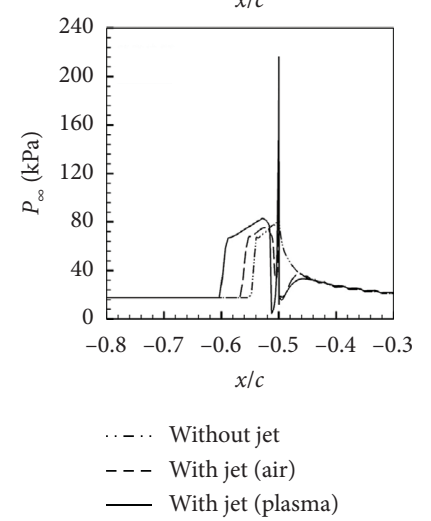

(b)

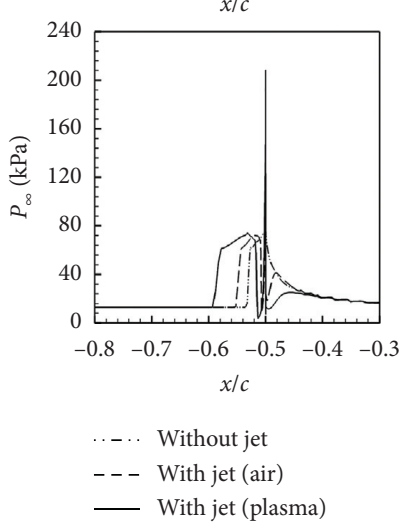

(c)

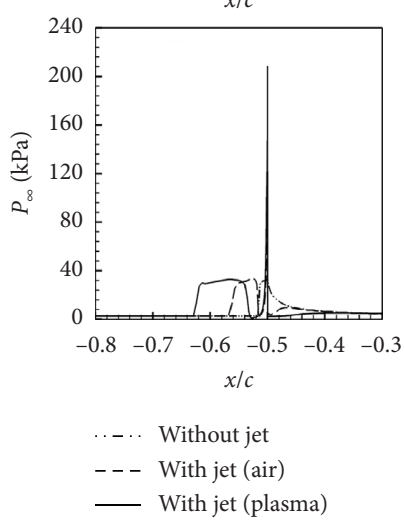

(d)

FIGURE 13: Comparison of Mach contours at constant $\mathrm{PR}=3$, and $M_{j}=1$ also include changes in pressure with increasing Mach number. (a) $M_{\infty}=1.4$, (b) $M_{\infty}=1.8$, (c) $M_{\infty}=2$, and (d) $M_{\infty}=3$.

The comparison of Mach contours for without jet, air (conventional), and plasma jets with its respective variation in pressure over the surface of an airfoil with increasing Mach is demonstrated in Figures 13(a)-13(d). The comparison of Mach contours depicts that, at high Mach, less PR ratio is required to attain the Mach disc. The increment in Mach number strengthens the bow shock, as the total pressure downstream of the shock decreases. This decline in pressure behind the shock reduced the pressure in recirculation regions; as a result, the static pressure ratio of jet increases [55].
For conventional jet $M_{\infty}$ at 1.4 and 1.8 , the unstable flow structure is developed due to subordinate jet performance and gives rise to a high drag value. In contrast, the counterflow plasma jet exhibits a stable SPM mode even at low Mach $\left(M_{\infty}=1.4\right.$ and 1.8) with appropriate recirculation regions and visible Mach disc. The Mach disc matures at $M_{\infty}=2$ in counterflow plasma, SPM mode retains, and a significant reduction in the drag coefficient occurs. However, in the conventional jet, the SPM mode is achieved at relatively high Mach $\left(M_{\infty}=(2)\right.$ having recirculation regions and Mach disc. At $M_{\infty}=3$, 


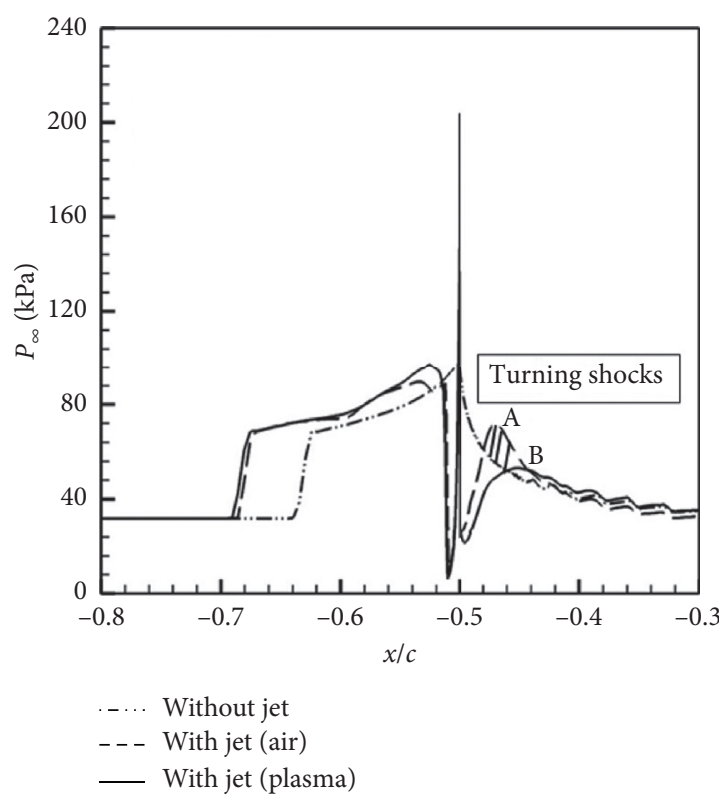

(a)

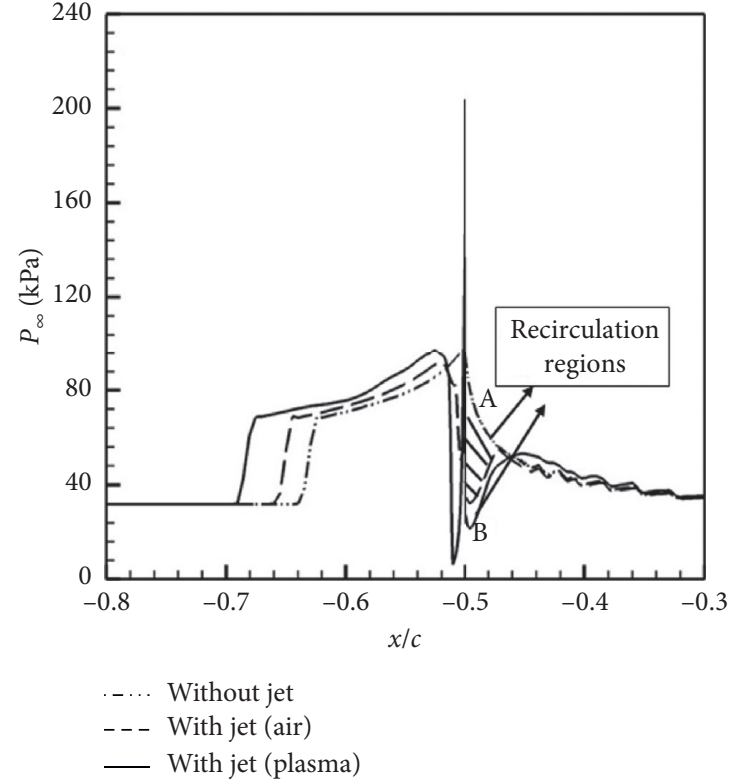

(b)

Figure 14: Comparison of change in pressure due to the turning shocks and the recirculation regions. (a) Pressure rise caused by turning shocks. (b) Reduction in pressure due to recirculation regions.

the jet is more underexpanded for the counterflow plasma jet and the Mach disc does not sustain its shape, but in the case of the conventional jet, the SPM mode persists itself with a noticeable Mach disc.

In Figures 13(a)-13(d), the comparison in depletion of pressure values between the conventional and plasma jet at the stagnation point of the airfoil are plotted. The counterflow plasma jet displaces the stagnation point to a remarkable distance, creates a large shock stand-off distance as compared to a conventional jet, and causes considerable reduction in drag ahead of an airfoil. The graphical comparison (Figure 14(b)) of without jet, conventional jet, and plasma jet is illustrated; for the counterflow plasma jet, the recirculation regions are large and expanded over the airfoil surface (point $B$ in Figure 14(b)). However, in the conventional jet, the shaded part point A in Figure 14(b) depicts that the compact recirculation regions are established and prevail in the leading edge region of airfoil.

In Figure 14(a), the sudden rise in pressure occurs after the displacement of shock. The recirculation region disintegrates at point $(x / c=-0.02)$ and generates turning shocks along the surface of the airfoil. In comparison to the conventional jet, the rise in pressure due to reattachment of shock in the counterflow plasma jet is less, as the recirculation regions in the plasma jet cover the large area of the airfoil, as shown in Figure 12(c). The hatched region in Figure 14(a) describes the difference in the length of turning shocks. The pressure value in the turning shocks is greater in the conventional jet (point $A$ ) as compared to the counterflow plasma jet (point $B$ ).
At high Mach $\left(M_{\infty}=3\right)$, the barrel shocks for the counterflow plasma jet are compressed and moves along the free-stream extending the recirculation regions over the airfoil surface. This squeezing of barrel shocks provides more room to jet outflow and yields a significant reduction in drag force.

5.2. Effect of Angle-of-Attack Variation. The other important variable that affects jet performance is the angle of attack. An increase in angle minimizes the jet performance of the conventional jet (Figures 15(a)-15(d)). Flow conditions for air and plasma jet remains same; $\mathrm{PR}=3, M_{\infty}=1.4$, and $M_{j}=1$. The interaction of shock with the stagnation point built a high value of drag for the no jet case. The employment of a counterflow jet (air or plasma) mitigates the drag effect by creating a large shock stand-off distance with increasing angles of attack.

The SPM mode sustained with the increase in the angle of attack $\left(\alpha_{\infty}\right)$ from $0^{\circ}$ to $4^{\circ}$ in the counterflow plasma jet. At higher angles of attack $\left(6^{\circ}\right.$ and $\left.8^{\circ}\right)$, the jet performance is reduced due to the introduction of strong flow asymmetry. The counterflow plasma jet tilt towards the windward side along the surface of an airfoil and the shock wave reattaches with the surface. On the contrary, conventional jet depicts inferior performance, and a strong flow asymmetry is introduced even at $2^{\circ}$. This asymmetry in the conventional jet persists and becomes stronger with the increasing angle of attack $\left(4^{\circ}\right.$ to $\left.8^{\circ}\right)$, as shown in Figures 15(a)-15(d). A small recirculation region allows the shock wave to attach near the leading edge of the airfoil. However, for the counterflow plasma jet, the recirculation region covers a large area of the airfoil's surface and the 

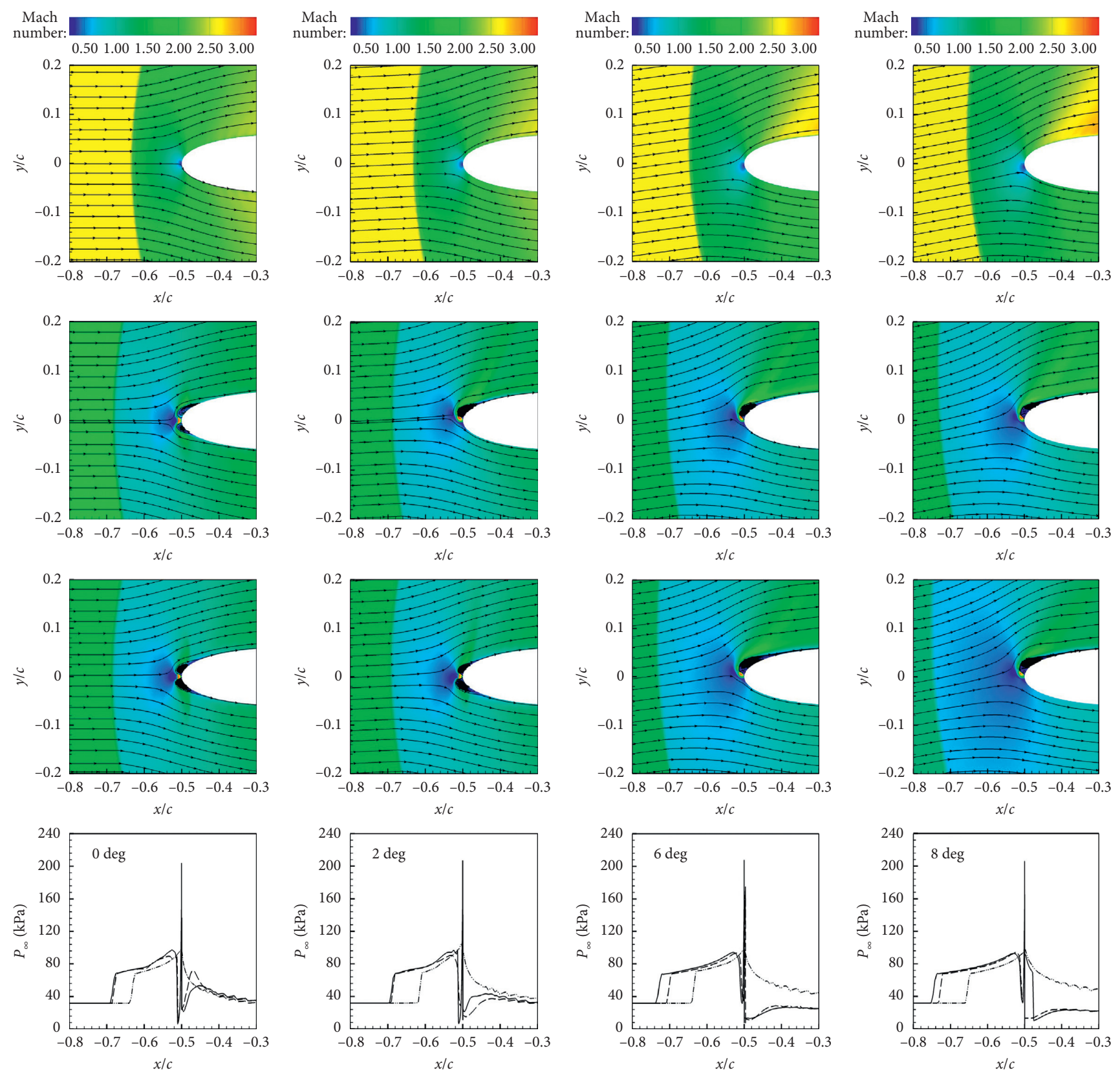

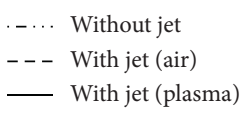

(a)

$$
\begin{aligned}
& -\ldots \text { Without jet } \\
& --- \text { With jet (air) } \\
& \_ \text {With jet (plasma) }
\end{aligned}
$$

(b)

$$
\begin{array}{ll}
-\ldots & \text { Without jet } \\
--- & \text { With jet (air) } \\
& \text { With jet }
\end{array}
$$

(c)

$$
\begin{array}{ll}
\ldots \ldots & \text { Without jet } \\
- & \text { With jet (air) } \\
& \text { With jet (plasma) }
\end{array}
$$

(d)

Figure 15: Surface pressure distribution with increasing angles of attack $\left(a=0^{\circ}\right.$ to $\left.8^{\circ}\right)$ at constant PR $=3.0$ and $M_{\infty}=1.4$. (a) $\alpha=0^{\circ}$. (b) $\alpha=2^{\circ}$. (c) $\alpha=6^{\circ}$. (d) $\alpha=8^{\circ}$.

shock reattachment occurs away from the nose of an airfoil. The comparison of pressure graphs for without jet, counterflow air, and plasma jet reinforce the above explanation.

\section{Conclusion}

In the present study, a detailed analysis of plasma generation in the plasma torch by the magnetohydrodynamic model (MHD) is examined. By controlling applied voltage and cathode temperature, required jet conditions $\left(M_{j}=1\right)$ were obtained at the nozzle exit. After numerical validation of the baseline experimental cases, the plasma nozzle is implemented on the conventional airfoil. The detailed comparison of flow characteristics between counter flow conventional (air) and plasma jet are investigated at Mach 1.4. The computational analysis depicts that a counterflow plasma jet provides $16 \%$ more reduction in drag as compared to a conventional counterflow jet. However, 
the plasma jet performance is influenced by the same parameters that affect the conventional jet performance:

(i) The jet stagnation temperature is the key parameter that affects the counterflow plasma jet. The hightemperature provides more ionization of gas, which enhances the mass flow rate of the plasma jet.

(ii) Analogous to the conventional jet, the plasma jet also exhibits inferior performance on the increment in angles of attack. At higher angles (beyond $\alpha_{\infty}=6$ ), for both jets (air and plasma), the jet tilt towards the free stream and cause increase in drag at the leading edge.

(iii) The flow field characteristics generated by counterflow jets (air and plasma) primarily depend on free-stream Mach. An increase in free-stream Mach amplifies the mass flow rate of conventional and plasma jets. However, compared to the conventional jet, the plasma jet achieves the SPM mode even at low Mach. The analysis depicts that the SPM mode is attained at Mach 1.8 for the plasma jet. With the further enhancement in Mach number $(M=3)$, the plasma jet becomes highly underexpanded and changes the Mach disc shape into convex curvature. In contrast to plasma, the air jet sustains its SPM mode at $M=3$ with a visible Mach disc.

\section{Data Availability}

The data used to support the findings of the study are available from the corresponding author upon request.

\section{Conflicts of Interest}

The authors declare that they have no conflicts of interest.

\section{References}

[1] X.-J. Zeng, J. Li, C. Cao, and H.-F. Shu, "Effect of a counterflow plasma jet on aerodynamics characteristic of a blunted cone," in Proceedings of the 28th International Symposium on Shock Waves, pp. 459-464, Springer, Berlin, Germany, 2012.

[2] B. Gunston, Faster than Sound: The Story of Supersonic Flight, Haynes Publishing, Sparkford, UK, 2008.

[3] J. Hartmann, "On a new method for the generation of soundwaves," Physical Review, vol. 20, no. 6, pp. 719-727, 1922.

[4] P. B. Burbank and R. L. Stallings, Heat-transfer and Pressure Measurements on a Flat-Face Cylinder at a Mach Number Range of 2.49 to 4.44, National Aeronautics and Space Administration, 1959.

[5] E. Marquart, J. Grubb, and L. Utreja, "Bow shock dynamics of a forward-facing nose cavity," in Proceedings of the 11th Aeroacoustics Conference, p. 2709, Monterey, CA, USA, 1987.

[6] K. B. Yuceil and D. S. Dolling, "Nose cavity effects on blunt body pressure and temperatures at mach 5," Journal of Thermophysics and Heat Transfer, vol. 9, no. 4, pp. 612-619, 1995.

[7] S. I. Silton and D. B. Goldstein, "Use of an axial nose-tip cavity for delaying ablation onset in hypersonic flow," Journal of Fluid Mechanics, vol. 528, pp. 297-321, 2005.
[8] R. O. Piland and L. W. Putland, Zero-Lift Drag of Several Conical and Blunt Nose Shapes Obtained in Free Flight at Mach Numbers of 0.7 to 1, Vol. 3, NACA, Boston, MA, USA, 1954.

[9] J. R. Stalder and H. V. Nielsen, Heat Transfer from a Hemisphere-Cylinder Equipped with Flow-Separation Spikes, National Advisory Committee for Aeronautics, Washington, DC, USA, 1954.

[10] S. M. Bogdonoff and I. E. Vas, "Preliminary investigations of spiked bodies at hypersonic speeds," Journal of the Aerospace Sciences, vol. 26, no. 2, pp. 65-74, 1959.

[11] H. Kobayashi, Y. Maru, and K. Fukiba, "Experimental study on aerodynamic characteristics of telescopic aerospikes with multiple disks," Journal of Spacecraft and Rockets, vol. 44, no. 1, pp. 33-41, 2007.

[12] J. P. Reding, R. A. Guenther, and B. J. Richter, "Unsteady aerodynamic considerations in the design of a drag-reduction spike," Journal of Spacecraft and Rockets, vol. 14, no. 1, pp. 54-60, 1977.

[13] S. Kim and H. J. Lee, "Influence of laser energy deposition conditions on the drag of a sphere in supersonic flow," Energies, vol. 12, no. 20, p. 3914, 2019.

[14] G. Watts, An Experimental Investigation of a Sonic Jet Directed Upstream against a Uniform Supersonic Flow, Institute of Aerophysics, Bengaluru, India, 1956.

[15] E. S. Love, The Effects of a Small Jet of Air Exhausting from the Nose of a Body of Revolution in Supersonic Flow, National Advisory Committee for Aeronautics, Washington, DC, USA, 1952.

[16] M. Barzegar Gerdroodbary, S. Bishehsari, S. M. Hosseinalipour, and K. Sedighi, "Transient analysis of counterflowing jet over highly blunt cone in hypersonic flow," Acta Astronautica, vol. 73, pp. 38-48, 2012.

[17] E. O. Daso, V. E. Pritchett, T.-S. Wang, D. K. Ota, I. M. Blankson, and A. H. Auslender, "Dynamics of shock dispersion and interactions in supersonic freestreams with counterflowing jets," AIAA Journal, vol. 47, no. 6, pp. 1313-1326, 2009.

[18] B. Shen, W. Liu, and L. Yin, "Drag and heat reduction efficiency research on opposing jet in supersonic flows," Aerospace Science and Technology, vol. 77, pp. 696-703, 2018.

[19] R. Adams and P. Jarvinen, The Effects of Retrorockets on the Aerodynamic Characteristics of Conical Aeroshell Planetary Entry Vehicles, American Institute of Aeronautics and Astronautics, Reston, VA, USA, 1970.

[20] D. J. Romeo and J. R. Sterrett, "Flow field for sonic jet exhausting counter to a hypersonic mainstream," AIAA Journal, vol. 3, no. 3, pp. 544-546, 1965.

[21] Y. Kim, D.-M. Kim, T.-S. Roh, and H. J. Lee, "Drag reduction effect by counter-flow jet on conventional rocket configuration in supersonic/hypersonic flow," Journal of Aerospace System Engineering, vol. 14, no. 4, pp. 18-24, 2020.

[22] S.-B. Li, Z.-G. Wang, W. Huang, and J. Liu, "Effect of the injector configuration for opposing jet on the drag and heat reduction," Aerospace Science and Technology, vol. 51, pp. 78-86, 2016.

[23] S. Ölçmen, G. C. Cheng, R. Branam, and J. Baker, "Effects of counterflow jet on the performance of a generic rocket," Acta Astronautica, vol. 182, pp. 219-229, 2021.

[24] Y. Kim, T.-S. Roh, H. Huh, and H. J. Lee, "Study on the combined effect of various injection conditions on the drag reduction by a counter-flow jet in supersonic flow," Aerospace Science and Technology, vol. 98, Article ID 105580, 2020. 
[25] H. Yoon, H. J. Lee, B. J. Lee, and I.-S. Jeung, "Numerical study of the effects of a counterflow jet on the drag reduction of a blunt body in a hypersonic flow," International Journal of Aeronautical and Space Sciences, vol. 19, no. 4, pp. 828-835, 2018.

[26] A. Bibi, A. Maqsood, S. Sherbaz, and L. Dala, "Drag reduction of supersonic blunt bodies using opposing jet and nozzle geometric variations," Aerospace Science and Technology, vol. 69, pp. 244-256, 2017.

[27] K. Hayashi, S. Aso, and Y. Tani, "Numerical study on aerodynamic heating reduction by opposing jet," AIAA Journal, vol. 66, no. 1, 2013.

[28] R. Yisheng, "Drag reduction research in supersonic flow with opposing jet," Acta Astronautica, vol. 91, pp. 1-7, 2013.

[29] W. Huang, R.-R. Zhang, L. Yan, M. Ou, and R. Moradi, "Numerical experiment on the flow field properties of a blunted body with a counterflowing jet in supersonic flows," Acta Astronautica, vol. 147, pp. 231-240, 2018.

[30] C. H. E. Warren, "An experimental investigation of the effect of ejecting a coolant gas at the nose of a bluff body," Journal of Fluid Mechanics, vol. 8, no. 3, pp. 400-417, 1960.

[31] E. A. Barber, "An experimental investigation of stagnationpoint injection," Journal of Spacecraft and Rockets, vol. 2, no. 5, pp. 770-774, 1965.

[32] J. S. Shang, "Plasma injection for hypersonic blunt-body drag reduction," AIAA Journal, vol. 40, no. 6, pp. 1178-1186, 2002.

[33] P. Y. Georgievsky and V. Levin, "Supersonic flow over bodies in the presence of external energy input," Pisma V Zhurn. Teh. Phiz, vol. 14, no. 8, pp. 684-687, 1988.

[34] G. Candler and J. Kelley, "Effect of internal energy excitation on supersonic blunt-body drag," in Proceedings of the 37th Aerospace Sciences Meeting and Exhibit, p. 418, Reno, NV, USA, 1999.

[35] Y. C. Ganiev, V. P. Gordeev, A. V. Krasilnikov, V. I. Lagutin, V. N. Otmennikov, and A. V. Panasenko, "Aerodynamic drag reduction by plasma and hot-gas injection," Journal of Thermophysics and Heat Transfer, vol. 14, no. 1, pp. 10-17, 2000.

[36] V. P. Gordeev, A. V. Krasil'nikov, V. I. Lagutin, and V. N. Otmennikov, "Experimental study of the possibility of reducing supersonic drag by employing plasma technology," Fluid Dynamics, vol. 31, no. 2, pp. 313-317, 1996.

[37] V. Fomin, A. Maslov, V. Fomichev et al., Experimental Investigation of Counterflow Plasma Jet in Front of Blunted Body for High Mach Number Flows, 2 Work, pp. 112-115, IVT RAS, Moscow, Russia, 2000.

[38] V. M. Fomin, A. A. Maslov, N. D. Malmuth et al., "Influence of a counterflow plasma jet on supersonic blunt-body pressures," AIAA Journal, vol. 40, no. 6, pp. 1170-1177, 2002.

[39] V. Fomin, A. Maslov, N. Malmuth, A. Shashkin, and T. Korotaeva, Numerical Investigation of Counterflow Jet Penetration in Hypersonic Flow, 2018.

[40] K. Hayashi and S. Aso, "Effect of pressure ratio on aerodynamic heating reduction due to opposing jet," in Proceedings of the 36th AIAA Thermophysics Conference, Orlando, FL, USA, 2003.

[41] N. Malmuth, V. Fomin, A. Maslov et al., "Influence of a counterflow plasma jet on supersonic blunt body pressures," in Proceedings of the 9th International Space Planes and Hypersonic Systems and Technologies Conference, p. 4883, Glasgow, Scotland, 1999.

[42] S. Rashid, F. Nawaz, A. Maqsood, R. Riaz, and S. Salamat, "Shock reduction through opposing jets-aerodynamic performance and flight stability perspectives," Applied Sciences, vol. 10, no. 1, p. 180, 2020.

[43] S.-H. Liu, J. P. Trelles, A. B. Murphy et al., "Numerical simulation of the flow characteristics inside a novel plasma spray torch," Journal of Physics D: Applied Physics, vol. 52, no. 33, Article ID 335203, 2019.

[44] B. Jodoin, P. Proulx, and Y. Mercadier, "Numerical study of supersonic direct current plasma nozzle flow," AIAA Journal, vol. 36, no. 4, pp. 578-584, 1998.

[45] J. P. Trelles, E. Pfender, and J. V. R. Heberlein, "Modelling of the arc reattachment process in plasma torches," Journal of Physics D: Applied Physics, vol. 40, no. 18, pp. 5635-5648, 2007.

[46] A. Lebouvier, C. Delalondre, F. Fresnet et al., "Three-dimensional unsteady mhd modeling of a low-current highvoltage nontransferred dc plasma torch operating with air," IEEE Transactions on Plasma Science, vol. 39, no. 9, pp. 1889-1899, 2011.

[47] R. Huang, H. Fukanuma, Y. Uesugi, and Y. Tanaka, "Comparisons of two models for the simulation of a dc arc plasma torch," Journal of Thermal Spray Technology, vol. 22, no. 2-3, pp. 183-191, 2013.

[48] P. Zihan, Y. Lei, Q. Shulou et al., "Comparison of Reynolds average Navier-Stokes turbulence models in numerical simulations of the dc arc plasma torch," Plasma Science and Technology, vol. 22, no. 2, Article ID 025401, 2019.

[49] H. K. Versteeg and W. Malalasekera, An Introduction to Computational Fluid Dynamics: The Finite Volume Method, Pearson Education, London, UK, 2007.

[50] A. B. Murphy and C. J. Arundelli, "Transport coefficients of argon, nitrogen, oxygen, argon-nitrogen, and argon-oxygen plasmas," Plasma Chemistry and Plasma Processing, vol. 14, no. 4, pp. 451-490, 1994.

[51] M. I. Boulos, P. Fauchais, and E. Pfender, Thermal Plasmas: Fundamentals and Applications, Springer Science \& Business Media, New York, NY, USA, 2013.

[52] R. Huang, H. Fukanuma, Y. Uesugi, and Y. Tanaka, "An improved local thermal equilibrium model of $\mathrm{dc}$ arc plasma torch," IEEE Transactions on Plasma Science, vol. 39, no. 10, 2011.

[53] Q. Zhou, H. Li, X. Xu et al., "Comparative study of turbulence models on highly constricted plasma cutting arc," Journal of Physics D: Applied Physics, vol. 42, no. 1, Article ID 015210, 2008.

[54] S. E. Selezneva, M. Rajabian, D. Gravelle, and M. I. Boulos, "Study of the structure and deviation from equilibrium in direct current supersonic plasma jets," Journal of Physics D: Applied Physics, vol. 34, no. 18, pp. 2862-2874, 2001.

[55] M. Fujita, "Axisymmetric oscillations of an opposing jet from a hemispherical nose," AIAA Journal, vol. 33, no. 10, pp. 1850-1856, 1995. 